\title{
CRISIS Y PERVIVENCIA DE LOS PAISAJES VITIVINÍCOLAS EN LOS BORDES DE CASTILLA Y LEÓN: DINÁMICA, ESTRATEGIAS E INSTRUMENTOS CONTRA EL ABANDONO Y LA PÉRDIDA DE VALORES PATRIMONIALES
}

\author{
Eugenio Baraja Rodríguez \\ Universidad de Valladolid \\ baraja@fyl.uva.es \\ ORCID iD: https://orcid.org/0000-0002-9712-7993 \\ Daniel Herrero Luque \\ Universidad de Burgos \\ dhluque@ubu.es \\ ORCID iD: https://orcid.org/0000-0002-0683-8942
}

Recibido: 20/12/2019; Aceptado: 29/07/2020

Cómo citar este artículo / citation: Baraja Rodríguez, Eugenio y Herrero Luque, Daniel (2020). Crisis y pervivencia de los paisajes vitivinícolas en los bordes de Castilla y León: dinámica, estrategias e instrumentos contra el abandono y la pérdida de valores patrimoniales. Estudios Geográficos, 81 (289), e045. https://doi.org/10.3989/estgeogr.202059.059

RESUMEN: En las últimas décadas están emergiendo en la escena vitivinícola de Castilla y León espacios tradicionales hasta ahora afectados por la crisis y el abandono. Vienen impulsados por nuevos actores que desarrollan iniciativas tan atentas a la calidad del vino como al territorio en el que se cultiva la vid. Las particulares condiciones del medio en el que se asientan los viñedos, confieren a estos espacios una singularidad paisajística difícilmente comparable, pero también dificulta su manejo y compromete la rentabilidad del cultivo, ocasionando su abandono con el consiguiente deterioro ambiental y pérdida de un valioso patrimonio cultural.

Este artículo analiza la evolución de estos espacios vitivinícolas emergentes e indaga en las posibilidades que ofrecen iniciativas y medidas que tienen como finalidad corregir el abandono y el deterioro de los valores paisajísticos y patrimoniales de los viñedos en las Denominaciones de Origen Protegidas (DOPs) "Sierra de Francia”, “Cebreros", "el Bierzo" y "Arribes". Metodológicamente, se recurre al análisis de los datos oficiales, a la elaboración cartográfica y a las entrevistas con actores relevantes. Las conclusiones apuntan al valor desigual que están teniendo estas medidas y abundan en los retos que tienen ante sí los distintos agentes involucrados en la gestión de paisajes agrarios de alto valor patrimonial en entornos particularmente frágiles.

PALABRAS CLAVE: Paisaje, viñedo, patrimonio, reservas de la Biosfera, banco de tierras, medidas agroambientales.

\section{CRISIS AND SURVIVAL OF THE WINE LANDSCAPES ON THE EDGES OF CASTILLA Y LEÓN: DYNAMICS, STRATEGIES AND INSTRUMENTS AGAINST ABANDONMENT AND LOSS OF HERITAGE VALUES}

ABSTRACT: In recent decades, traditional areas, which have been affected by the crisis and neglected by the population, are emerging on the Castilla y León wine scene. New players, who are developing initiatives that are as attentive to the quality of wine as they are to the landscape in which the wines are grown, promote these areas. The particular conditions of the environment in which the vineyards are located build in these areas a unique landscape, difficult to compare. Nevertheless, it also makes them more difficult to manage and compromises the crop profitability, causing its abandonment, with the consequent environmental deterioration and loss of a valuable cultural heritage.

This article analyses the evolution of these emerging winemaking spaces and investigates the possibilities offered by different initiatives and measures aimed at correcting land abandonment and the deterioration of the landscape and heritage values of the vineyards, under the Protected Designations of Origin "Sierra de Francia", "Cebreros", "el Bierzo" and "Arribes". Methodologically, the project analyses official data, mapping and interviews with relevant stakeholders. The conclusions point out the unequal impact of this kind of measures and they abound in the challenges faced by the various agents involved in the management of those agricultural landscapes of high heritage value in fragile environments.

KEYWORDS: Heritage, vineyard, landscape, Biosphere reserves, land bank, agri-environmental measures.

Copyright: ( 2020 CSIC. Este es un artículo de acceso abierto distribuido bajo los términos de la licencia de uso y distribución Creative Commons Reconocimiento 4.0 Internacional (CC BY 4.0). 


\section{INTRODUCCIÓN}

El sector vitivinícola se ha convertido en una pieza clave de la economía de Castilla y León y en uno de los pilares sobre los que se asienta el desarrollo de no pocas de sus comarcas agrarias. Con las primeras denominaciones de origen (DO) (Rueda, en 1980; Ribera del Duero, en 1982; Toro, en 1987), la vitivinicultura de la región inició un camino orientado a poner en el mercado vinos de calidad adaptados al gusto del consumidor internacional. Alonso, Aparicio y Sánchez (2003) analizaron este proceso de cualificación del complejo vitivinícola, articulándolo en una serie de etapas: la de autoabastecimiento (anterior a 1960), la de modernización productiva (1960-1975), la de crisis y recomposición (1975-1985) y la de innovación y estallido espacial (a partir de 1985). En la actualidad, los viñedos de Castilla y León se integran, en su mayor parte, en esa red institucionalizada de comarcas vitícolas de calidad diferenciada sobre la que se ha asentado la necesaria cooperación entre agentes para afrontar los "cambios e innovaciones tanto de proceso y producto como de organización, gestión y comercialización" (Alonso et al., 2003, p. 109). Una red (Figura 1) que está constituida por trece Denominaciones de Origen Protegidas (DOPs), que agrupa nueve DO (Ribera del Duero, Cigales, Rueda, Toro, Bierzo, Arlanza, Arribes, Tierras de León y Tierra del Vino de Zamora) y cuatro denominaciones de vinos de calidad (VC) (Sierra de Salamanca, Valtiendas, Valles de Benavente y Cebreros), a las que habría que agregar una indicación geográfica protegida de vinos de la tierra (VT) (Castilla y León) y una DOP supraautonómica (Rioja, que integra una parte de Burgos). Por otro lado, su pujanza económica se pone en evidencia al constatar que el sector vitivinícola mueve 900 millones de euros y da empleo a más de 19.000 personas, de las cuales 15.500 son viticultores y otras 3.300 trabajan directamente en las más de 650 bodegas registradas (Junta de Castilla y León, 2018) ${ }^{1}$.

Pero estas cifras no deben ocultar la diversidad de la viticultura en la región más extensa y variada de España. Pese a que, como concluían los autores anteriormente citados, "la consolidación del proceso innovador y la creación de una cultura productora de base territorial en las comarcas pioneras ha impulsado la difusión del modelo productivo en red hacia otras comarcas menos avanzadas" (Alonso et al., 2003 , p. 120), hoy ese dinamismo sigue concentrado en determinados territorios vitivinícolas, particularmente en la Ribera del Duero, Rueda, Toro y, en menor medida, Cigales. En estas comarcas se cultivan casi las dos terceras partes del viñedo de Castilla y León (48.881 de las 77.791 ha en 2017) (Figura 1) y se mueve buena parte del negocio que gira alrededor del vino. Son los espacios más pujantes, abiertos a la continua mejora técnica de toda la cadena de valor que se genera desde el campo (mecanización de tareas, control de plagas y enfermedades, selección de clones, etc.) hasta las cada vez más sofisticadas bodegas (trazabilidad, levaduras, etc.). También donde van a parar las mayores inversiones de las líneas de apoyo a la innovación que tiene abiertas la administración.

Como resultado de todo ello, el paisaje vitivinícola de estas comarcas se ha transformado sustancialmente. Las viñas, soportadas en espaldera por conducciones que llevan asociados sistemas de riego, se distribuyen en marcos de plantación adaptados a la mecanización integral en grandes parcelas salpicadas por bodegas de cuidada arquitectura.

Estas han ido abandonando sus lugares tradicionales de ubicación (en el subsuelo de los pueblos o en barrios horadados en las laderas más compactas) para localizarse cerca de las principales vías de comunicación. Se trata de nuevos paisajes que revelan una organización espacial adaptada a los tiempos de la globalización, que tienen poco que ver con los que existían en los años ochenta del siglo pasado (cuando comenzó el proceso innovador), por más que los reconozcamos como herederos de una tradicional cultural vitícola y vinícola.

Estos paisajes conservan los rasgos de autenticidad, entendida como "el mantenimiento continuado y secular sobre el espacio de la función productiva adaptada al entorno (...) sin esclerotizaciones que detengan el proceso de progresión ni promuevan la creación de falsos históricos" (Martínez, Baraja y Molinero, 2019 , p. 19), pero su integridad, por esta misma razón, es más discutible. Esto no ha impedido que, consolidada su presencia en el mercado de los vinos de calidad, y como rasgo propio de una nueva etapa, aparezcan actividades que tienden a diversificar el negocio del vino. Entre ellas, el enoturismo se está afianzando como una estrategia productiva territorialmente decisiva (Fernández y Vidal, 2018). Castilla y León ya ocupa un destacado lugar al contar con ocho de las treinta rutas del vino certificadas en 2018 y atraer al $17 \%$ de los visitantes que acuden a las bodegas y museos del vino en España.

Sin embargo, no todos los espacios vitivinícolas se han configurado bajo similares modelos productivos. 
FIGURA 1

DISTRIBUCIÓN DE LA SUPERFICIE DE VIÑEDO POR MUNICIPIO EN CASTILLA Y LEÓN EN 2017

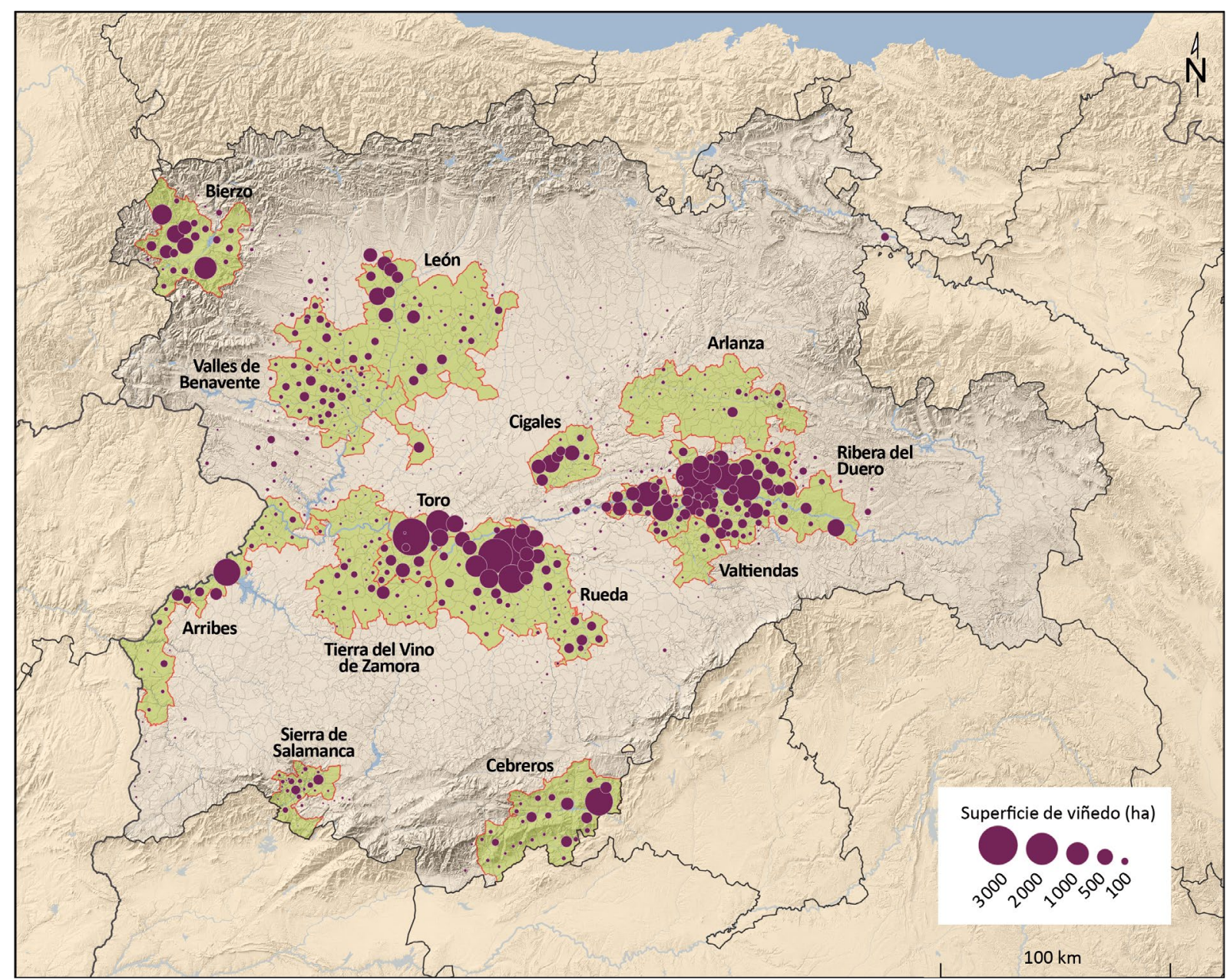

Fuente: Relación de las superficies de cultivos leñosos. Junta de Castilla y León.

Ocurre en otras comarcas de las llanuras, en las DOPs Arlanza, León, Tierra del Vino, Valles de Benavente y Valtiendas; pero es en los espacios del borde donde, frente a "este cambio globalizador y homogeneizador se opone la resiliencia de algunas comarcas tradicionales que ni siquiera basan su especialización en el viñedo, pero que no solo cuentan con paisajes auténticos sino también íntegros" (Martínez et al., 2019, p. 20). Es el caso de los viñedos de la comarca fronteriza de Arribes del Duero (DOP Arribes); los de la DOP Sierra de Salamanca; también los de la DOP Cebreros e, incluso, los de la DOP Bierzo (una de las pioneras, con DO reconocida en 1989) y, en general, en aquéllos en los que las condiciones del medio imponen unas formas de producción especialmente difíciles.
Son viñedos que surgieron hace siglos en medios frágiles y que hoy son reductos, en muchos casos, de un tipo de economía agraria desaparecida. Sirven de base para la elaboración de vinos que, por variedad y tipicidad, están encontrando una forma de inserción competitiva en este difícil mercado y están siendo reconocidos como tales (Vinos.Wine, 2018) ${ }^{2}$; y lo hacen de la mano de nuevos actores que desarrollan iniciativas tan atentas al producto final (la calidad del vino) como a los valores materiales e inmateriales del paisaje que expresa su carácter ${ }^{3}$. Las singulares condiciones del medio -particularmente su anfractuosidad- determinan la organización de un terrazgo muy fragmentado, compuesto por múltiples parcelas en pendientes pronunciadas, muchas veces dispuestas en bancales, terrazas y paredones, donde perviven 
marcos de plantación históricos, cepas antiguas y variedades viníferas únicas. Es un hecho que les confiere una singularidad paisajística difícilmente comparable, de tal forma que "beber el paisaje" se ha convertido en un eslogan ampliamente difundido en la promoción que las bodegas hacen de estos vinos, y que abunda en la calidad ambiental y cultural de los entornos en los que se producen.

El paisaje y sus atributos patrimoniales se presentan como claves de una estrategia tendente a poner en valor aquellos aspectos que les singularizan, al haber quedado al margen de la homogeneización modernizadora experimentada por el cultivo de la vid y la elaboración de vinos en los territorios más dinámicos. En suma, en la línea temática del presente número monográfico, ejemplifican, en el mundo del vino, el papel que juegan los sistemas agroalimentarios enraizados territorialmente frente a la vitivinicultura tecnológica de proyección global.

Sin embargo, este camino no está exento de dificultades. Las mismas condiciones naturales que avalan su singularidad constituyen un serio condicionante para su futuro, en tanto que el trabajo que exige el cuidado de estos viñedos explica los cambios en su ubicación (permanencia o traslado a los entornos más accesibles), la reducción de su superficie $y$, en última instancia, su abandono, con los consiguientes problemas ambientales y la pérdida de un valioso patrimonio cultural.

\section{OBJETIVOS, FUENTES Y MÉTODO}

En este contexto, se plantean las siguientes cuestiones. ¿Cuáles han sido los factores que explican la trayectoria de estos espacios vitivinícolas, que han transitado desde la marginación o el abandono hasta reaparecer ahora en clave postproductivista? ¿Cuáles están siendo sus estrategias de supervivencia? ¿A qué dificultades se enfrentan? ¿Qué iniciativas se están desarrollando para superarlas? El presente artículo tiene como objetivo responder a las anteriores preguntas, pero también poner de manifiesto las posibilidades que en estos espacios resilientes, no orientados directamente a la producción en cantidad sino a fortalecer su calidad y diferenciación, ofrecen las herramientas o instrumentos jurídico-administrativas diseñados para corregir o mitigar el abandono de los cultivos, en general, y del viñedo en particular, en entornos donde las prácticas agrarias son particularmente difíciles.

Se considera, en primer lugar, el banco de tierras de viñedo, cuya puesta en marcha ha sido reciente- mente anunciada por la DOP Sierra de Salamanca (Serrano, 2017), pero que lleva ya desde 2013 desarrollándose en el Bierzo como una estrategia de lucha contra el abandono de las viñas. En segundo lugar, se indaga en el alcance de las medidas tendentes al mantenimiento de los cultivos permanentes en paisajes singulares, posiblemente la medida agroambiental, prevista en el Programa de Desarrollo Rural de Castilla y León 2014-2020, más directamente involucrada o comprometida con estos paisajes. Se concluye planteando propuestas al reto que tienen ante sí los responsables de los distintos espacios naturales y culturales en los que están insertos estos territorios vitivinícolas a la hora de gestionar el paisaje, incidiendo particularmente en el caso de las Reservas de la Biosfera (RB), que afecta enteramente a dos de estos espacios (DOP Sierra de Salamanca y DOP Arribes) y parcialmente a otro (DOP Bierzo).

Para ello, se ha recurrido al análisis de fuentes estadísticas convencionales (pliegos de condiciones de las DOPs; documentos $1 \mathrm{~T}$ y registro municipal de cultivos de la administración regional; estadísticas agrarias e informes del Ministerio de Agricultura sobre los vinos con DOP, etc.) para elaborar las estadísticas generales y realizar mapas temáticos relativos a la dinámica de los distintos territorios de la vid y el vino en Castilla y León. También se han confeccionado nuevas bases de datos a partir de la información que proporciona el Sistema de Información Geográfica de Parcelas Agrícolas (SIGPAC) de 2019 y el Modelo Digital del Terreno de Castilla y León, con el fin de alcanzar mayor precisión en la cartografía y ponderación de la superficie real, en la ubicación y en la dinámica de los viñedos. Se han analizado, igualmente, la relación de ayudas concedidas por la Junta de Castilla y León en el marco de las medidas agroambientales y de clima, así como los datos de los informes de actividades del Banco de Tierras del Bierzo. Se han considerado los distintos planes directores de las Reservas de la Biosfera implicadas y, por último, se ha recurrido a entrevistas con los responsables de los consejos reguladores de las DOP analizadas y de la Gerencia del Banco de Tierras del Bierzo.

\section{RESULTADOS Y DISCUSIÓN}

Del análisis de las fuentes consultadas y de la información cualitativa obtenida en las entrevistas, se deduce el desigual impacto de las medidas que se están aplicando con la finalidad de mitigar el abandono y mantener los elementos patrimoniales de los 
paisajes vitivinícolas emergentes en Castilla y León. No obstante, antes de profundizar en esta cuestión, resulta oportuno valorar las características y dinámica de estos territorios singulares.

\section{Crisis y pervivencia de los paisajes vitivinícolas tradicionales en entornos difíciles}

La evolución de la superficie de viñedo en Castilla y León, desde que se pusieron en marcha las primeras denominaciones de origen en la década de los ochenta (Rueda, en 1980; Ribera de Duero, en 1982; Toro, en 1987), marca una trayectoria divergente. En conjunto, utilizando las estadísticas municipales de cultivos para Castilla y León (Tabla 1), podemos observar que se ha pasado de las 92.369 ha cultivadas en 1985 a las 77.791 ha en 2017 (la superficie contabilizada a través de los polígonos SIGPAC/SIOSE de 2019 rebaja esa cifra a 75.882,2 ha) ${ }^{4}$.

Sin embargo, esta trayectoria es desigual. Crece de forma notable en los territorios más dinámicos y pujantes distribuidos por los páramos, campiñas, valles y terrazas del centro de la cuenca del Duero (Ribera del Duero, Rueda, Toro y, en menor medida, Cigales), mientras que los bordes serranos o montañosos (Cebreros, el Bierzo, Sierra de Salamanca y Arribes) experimentan una clara reducción (Figura 2).

Los primeros viñedos representan el arquetipo que más se ha impulsado y dado fama a los vinos del Duero: los que "con su imagen de control y calidad [...] identifican con nitidez a los buenos vinos de Castilla y León en los mercados "(Alonso et al., 2003, p. 109). Los tres territorios que el Duero hilvana en su cuenca, ilustran esta tipología singularizada por llevar hasta sus máximas consecuencia "los cambios e innovaciones tanto de proceso y producto como de organización, gestión y comercialización" (Alonso et al., p. 108). Rueda fue la primera DO de la región (1982). Hoy abarca un total de 72 municipios que tienen su centro en el considerado triángulo de oro del verdejo, cuyos vértices se sitúan en Rueda, La Seca y Serrada (Valladolid). Es aquí donde se ha conformado, por concentración, intensificación y especialización, lo que podríamos denominar paradigma de los viñedos proliferantes. Solo en términos de

TABLA 1

EVOLUCIÓN DE LA SUPERFICIE DE VIÑEDO EN LAS DENOMINACIONES DE ORIGEN PROTEGIDAS DE VINOS REGISTRADAS EN CASTILLA Y LEÓN

\begin{tabular}{|l|c|c|c|c|c|c|c|c|c|}
\hline \multirow{2}{*}{ DOPs de vinos en Castilla y León } & \multicolumn{3}{|c|}{1985} & \multicolumn{3}{|c|}{2017} & \multicolumn{3}{|c|}{$1985=100$} \\
\cline { 2 - 11 } & Secano & Regadío & Total & Secano & Regadío & Total & Secano & Regadío & Total \\
\hline Arlanza & 1881 & 3 & 1884 & 925 & 25 & 950 & 49,2 & 833,3 & 50,4 \\
\hline Arribes & 5838 & & 5838 & 3190 & 1 & 3191 & 54,6 & & 54,7 \\
\hline Bierzo & 8162 & & 8162 & 5147 & 7 & 5154 & 63,1 & & 63,1 \\
\hline Cebreros & 8601 & 37 & 8638 & 3932 & 0 & 3932 & 45,7 & 0,0 & 45,5 \\
\hline Cigales & 2555 & & 2555 & 2332 & 181 & 2513 & 91,3 & & 98,4 \\
\hline León & 16405 & & 16405 & 5721 & 41 & 5762 & 34,9 & & 35,1 \\
\hline Ribera del Duero & 12233 & 13 & 12246 & 22026 & 1104 & 23130 & 180,1 & 8492,3 & 188,9 \\
\hline Rueda & 7425 & & 7425 & 13287 & 3249 & 16536 & 178,9 & & 222,7 \\
\hline Sierra de Salamanca & 2042 & 1 & 2043 & 1013 & 3 & 1016 & 49,6 & 300,0 & 49,7 \\
\hline Tierra del Vino & 3272 & 13 & 3285 & 1630 & 38 & 1668 & 49,8 & 292,3 & 50,8 \\
\hline Toro & 5894 & 25 & 5919 & 6399 & 303 & 6702 & 108,6 & 1212,0 & 113,2 \\
\hline Valles de Benavente & 5221 & 2 & 5223 & 2605 & 4 & 2609 & 49,9 & 200,0 & 50,0 \\
\hline Valtiendas & 832 & & 832 & 368 & 2 & 370 & 44,2 & & 44,5 \\
\hline & & & & & & & & & \\
\hline Total en Castilla y León & 92269 & 100 & 92369 & 72576 & 5215 & 77791 & 78,7 & 5215,0 & 84,2 \\
\hline
\end{tabular}

Fuente: Documentos 1T 1985 y relación de las superficies de cultivos leñosos 2017.N.B.: Las superficies vitícolas de las distintas fuentes (1-T, Consejos reguladores e informes DOP) no coinciden exactamente, porque en algunos casos solo registran las superficies en producción. 


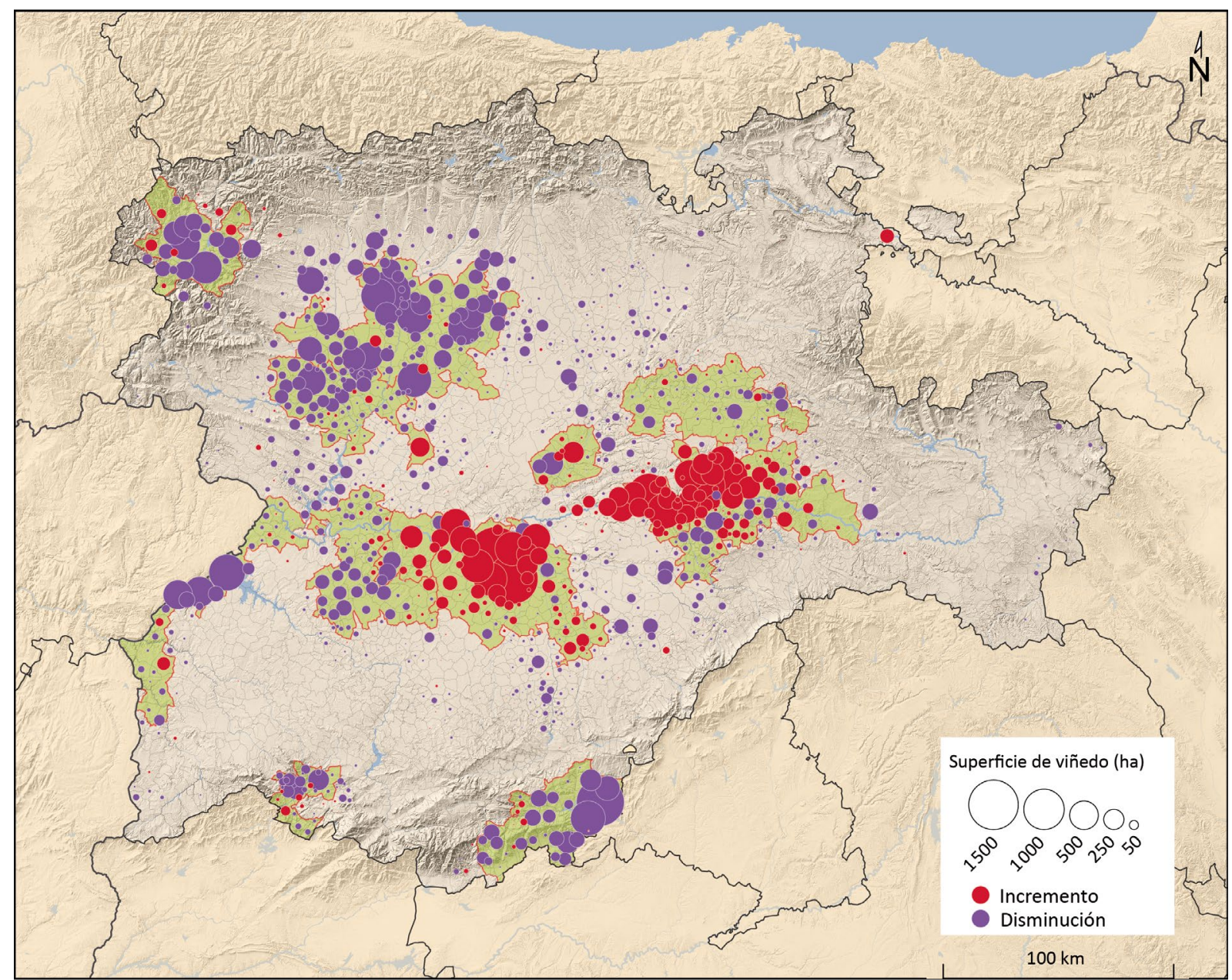

Fuente: Documentos 1T 1985 y relación de las superficies de cultivos leñosos 2017.

superficie cultivada, la progresión de este territorio es incuestionable. Si en 1985 se cultivaban 7.425 ha de viñedo, hoy se cuenta con una superficie de 19.246 ha (16.165 ha amparadas por la DO), de las que 3.250 se benefician del riego. En 2018, 1.540 agricultores vendimiaron 130 millones de kg de uva, que fue procesada en 69 bodegas, en torno a las cuales gira una buena parte de la actividad económica de la comarca (Alario, Morales y Molina, 2018).

Por otro lado, cuando en 1982 se reconoció la DO Ribera del Duero, apenas existían una veintena de bodegas cooperativas y algunas privadas, principalmente en tierras vallisoletanas y burgalesas. El arranque de las viñas era una práctica generalizada y en 1985 solo se cultivaban 12.233 ha. Desde entonces, comenzó el gran salto adelante de la viticultura ribe- reña, hoy una de las más dinámicas de Europa. En 2017 funcionaban, en el marco de la DO, 314 bodegas, y eran 23.130 las hectáreas cultivadas, de las cuales 1.104 se beneficiaban del riego y el 93\% estaban amparadas por esta DO.

Por último, la DO Toro, que se localiza en el extremo oriental de la provincia de Zamora, junto al Duero, comienza su andadura en el año 1987, momento en el que se aprueba el reglamento por el que se rige su Consejo Regulador con sede en la ciudad de Toro. Entonces, el viñedo había disminuido en esta DO hasta las 3.250 ha que cultivaban los 645 viticultores registrados, la mayor parte socios de unas cooperativas desmesuradas por su tamaño, que recogían la uva y elaboraban un vino poco adaptado al gusto que progresivamente demandaba el mercado. En la ac- 
tualidad, esta DO reúne a 60 bodegas repartidas entre 15 municipios de las provincias de Zamora y Valladolid, elabora 14 millones de botellas (2018) y la superficie del viñedo amparada alcanza las 5.800 ha (Plaza y Fernández, 2018).

En estos tres casos, la extensión del viñedo se ha incrementado de forma notable (espectacular en alguno de ellos). Si utilizamos los datos que proporcionan los documentos $1 T$ para 1985 y los comparamos con los del registro de cultivos a escala municipal de 2017, apreciamos que si para el conjunto de Castilla y León el índice 100 con base en 1985 ha pasado a 84,2 en 2017, en el caso de Rueda se ha incrementado hasta alcanzar el valor de 222,7; en Ribera del Duero, 188,9 y, en Toro, el índice ha subido hasta 113,2 . El número de bodegas ha seguido una trayectoria similar en el conjunto de las tres DO señaladas (186 en 2000/2001 y 443 en 2017/2018), evidenciando el impulso inversor que está detrás de este gran negocio.

Cigales, por otro lado, con 2.513 ha, apenas ha experimentado variación (índice 98,4), pues el arranque de viñedos tradicionales se ha compensado con nuevas plantaciones. Emplazados en su mayoría en las terrazas de la margen derecha del Pisuerga, en la provincia de Valladolid, la DO de Cigales se puso en marcha en 1991, y se ha convertido en uno de los referentes del vino rosado en la región (Fernández, 2018). En la actualidad (2017/18), da amparo a 388 viticultores, que cultivan 1.963 ha, y a 34 bodegas, que elaboran $25.043 \mathrm{hl}$ de vino.

Estas denominaciones son la excepción, pues en el resto de los territorios de la vid y el vino de Castilla y León, la superficie ha disminuido en mayor o menor medida. Es el caso de otros viñedos de la cuenca del Duero, como Arlanza, Tierra del Vino, Valles de Benavente, León o Valtiendas, cuyos viñedos se han reducido, en conjunto, a la mitad (Plaza, Fernández y Herrero, 2019). Pero, el verdadero contrapunto a esa dinámica la encontramos en los accidentados márgenes de la región. Allí se encuentran los restos, mejor o peor conservados, de lo que en su momento fueron los paisajes de una agricultura de montaña que, aprovechando las favorables condiciones termopluviométricas que proporciona el encajamiento y la exposición del sustrato físico sobre el que se asienta su terrazgo, posibilitó el desarrollo de una variedad de cultivos termófilos desconocidos en las llanuras del interior, donde, por altitud, se registra una integral térmica menor. Entre ellos, se encuentran unos viñedos singulares, a los que la anfractuosidad del medio limitó la posibilidad de adaptación a una viticultura moderna y a "un nuevo concepto en la elaboración del vino orientado a la formación de un sector avanzado y mecanizado, con incremento de la producción y la calidad" (Alonso et al., 2003 p. 116).

Estos espacios son los que, después de afrontar una aguda crisis, resurgen al aprovechar las ventajas de los nuevos valores postproductivistas (Binimelis, 2019; Ruiz, 2013), tendentes a recomponer la raíz natural y territorial de la agricultura y, por ello, más atentos a la diferenciación, a la singularidad y a la veracidad. Unos nuevos valores que "tienen mucho que ver con el paisaje, la ecología, la cultura, la justicia social y la alimentación saludable, conectando de forma directa con un concepto que en la última década está en boca de todos, el desarrollo sostenible" (Armesto, 2005, p. 140). Específicamente, nos referimos a los viñedos del Bierzo, de Cebreros, de Arribes y de la Sierra de Salamanca que, en conjunto, sumaban en 2017 una superficie de 13.293 ha (la mitad de las cuales se concentran en el Bierzo, como también lo hacen el grueso de las bodegas). Todos los paisajes, como es propio de los ámbitos de montaña, están marcados por la diversidad (Figuras 3, 4, 5 y 6), y muestran entre sí trayectorias contrastadas. Sin embargo, encierran algunos rasgos comunes que permiten su consideración conjunta como antítesis de los proliferantes.

El primer rasgo es que estos paisajes son exponentes de un tipo de agricultura casi germinal, como la que existía en espacios de montaña tradicional: aprovechan las favorables condiciones climáticas de la fosa del Alagón y sus barrancos abiertos al mediodía, en el caso de la DOP Sierra de Salamanca; la exposición solana de las vertientes orientadas al sur y sureste de los bloques que destacan sobre el Alberche y Tiétar en el gran murallón de la Cordillera Central, en el caso de la DOP Cebreros; el hundimiento, como una gran dovela, de la hoya del Bierzo o de la entalladura del Duero en los materiales paleozoicos de las penillanuras occidentales en la DOP Arribes, donde el viñedo compartía el terrazgo con olivares y otros frutales.

Era una agricultura singular, que conjugaba el autoconsumo y la integración económica con los espacios de llanura. Sin embargo, la anfractuosidad del medio, con grandes desniveles y fuertes pendientes, se avenía mal con el manejo tecnificado que los tiempos progresivamente imponían. El análisis de la información que proporcionan los polígonos del SIGPAC (Tabla 2), indica que la pendiente media del conjunto de los recintos 
alcanza 4,8 $\cong$ en Arribes, 6,7 $\cong$ en Cebreros, 7,4 en el Bierzo y 8,65 o en la Sierra de Salamanca. Algo que contrasta con espacios de llanuras, como Rueda (1,9 ) o Toro (2,3). Estas fuertes pendientes, que alcanzan valores máximos de 58 o en el Bierzo, de 45 o en Cebreros y de 41 ㅇ en la Sierra de Salamanca, han condicionado la naturaleza del terrazgo, a veces construido enteramente mediante bancales, paredones y terrazas de costoso mantenimiento. Este es uno de los rasgos que confiere carácter al paisaje de muchos de estos espacios, y, en el caso de Arribes y de la Sierra de Salamanca, actúa como verdadero vector patrimonial (Baraja, Plaza y Prada, 2017; Baraja, Herrero, Martínez y Plaza, 2019c).

Todo lo anterior es indisociable de otra condición igualmente limitadora: la fuerte fragmentación del terrazgo. El análisis de la información que proporcionan los polígonos del SIGPAC y el Modelo Digital del Terreno de Castilla y León da una idea del alcance de su fuerte compartimentación. En la región se contabilizan 242.414 recintos vitícolas distribuidos en 220.709 parcelas (Tabla 2). Su tamaño medio es de 0,313 ha/recinto. Mientras este tamaño, en el caso de la DO Rueda, se multiplica por seis (1,8 ha/recinto), en Cebreros solo llega a 0,182 ha/recinto; en Arribes, a 0,17 ha/recinto; a 0,1 ha/recinto en el Bierzo; y en la Sierra de Salamanca, a 0,099 ha/recinto. Es decir, a modo de mosaico, tal y como ocurre en el Bierzo, el terrazgo está compuesto por las múltiples teselas que representan parcelas donde, por sus pequeñas dimensiones, no resulta fácil la utilización de técnicas modernas de manejo. Estas condiciones de partida limitaron las transformaciones inherentes a la modernización productiva. Lentamente, desde los años sesenta, el estilo de organización tradicional (viticultores que elaboraban sus propios vinos y enviaban el resto a las cooperativas para producir graneles) se fue descomponiendo. Con ello, se acentuó el éxodo rural, la desagrarización y el abandono.

Hoy, 1.600 viticultores en Cebreros cultivan la viña (con una media de una o dos hectáreas), pero la mayoría no son profesionales, y solo 330 (con una media de 1,4 ha) están amparados por la DOP Vinos de Calidad de Cebreros. Entre los 207 viticultores amparados por la DO de Arribes, no faltan quienes se dedican a la actividad agraria a título principal, ampliando la

TABLA 2

DATOS SOBRE EL NÚMERO, LA SUPERFICIE Y LA PENDIENTE DE LAS PARCELAS DE CULTIVO DE VIÑEDO EN 2019 EN CASTILLA Y LEÓN

\begin{tabular}{|l|c|c|c|c|c|c|c|}
\hline \multicolumn{1}{|c|}{$\begin{array}{c}\text { DOPs de vinos en } \\
\text { Castilla y León }\end{array}$} & $\begin{array}{c}\text { Número de } \\
\text { recintos }\end{array}$ & $\begin{array}{c}\text { Número de } \\
\text { parcelas }\end{array}$ & $\begin{array}{c}\text { Superficie } \\
\text { total } \\
\text { hectáreas }\end{array}$ & $\begin{array}{c}\text { Superficie } \\
\text { media del } \\
\text { recinto de } \\
\text { viñedo (ha) }\end{array}$ & $\begin{array}{c}\text { Superficie } \\
\text { media de la } \\
\text { parcela de } \\
\text { viñedo (ha) }\end{array}$ & $\begin{array}{c}\text { Pendiente } \\
\text { media de la } \\
\text { superficie de } \\
\text { viñedo (o) }\end{array}$ & $\begin{array}{c}\text { Pendiente } \\
\text { máxima (o) }\end{array}$ \\
\hline Arlanza & 6258 & 5995 & 971,3 & 0,155 & 0,162 & 3,37 & 27 \\
\hline Arribes & 7390 & 6655 & 1301,7 & 0,176 & 0,196 & 4,78 & 32 \\
\hline Bierzo & 48064 & 45592 & 4956,1 & 0,103 & 0,109 & 7,41 & 58 \\
\hline Cebreros & 15607 & 13964 & 2841,4 & 0,182 & 0,203 & 6,57 & 45 \\
\hline Cigales & 4412 & 3968 & 2399,1 & 0,544 & 0,605 & 2,46 & 39 \\
\hline León & 15471 & 14202 & 3587,2 & 0,232 & 0,253 & 1,53 & 36 \\
\hline Ribera del Duero & 63412 & 56054 & 23631,7 & 0,373 & 0,422 & 3,48 & 41 \\
\hline Rueda & 10662 & 8118 & 19246,1 & 1,805 & 2,371 & 1,91 & 34 \\
\hline Sierra de Salamanca & 6183 & 5929 & 609,3 & 0,099 & 0,103 & 8,65 & 41 \\
\hline Tierra del Vino & 3733 & 3339 & 1871,7 & 0,501 & 0,561 & 2,76 & 29 \\
\hline Toro & 5473 & 4374 & 7037,2 & 1,286 & 1,609 & 2,37 & 30 \\
\hline Valles de Benavente & 22172 & 20726 & 2840,7 & 0,128 & 0,137 & 2,29 & 36 \\
\hline Valtiendas & 2009 & 1915 & 437,0 & 0,218 & 0,228 & 3,46 & 35 \\
\hline Resto de Castilla y León & 31568 & 29878 & 4151,7 & 0,132 & 0,139 & 4,02 & 51,00 \\
\hline Total en Castilla y León & 242414 & 220709 & 75882,2 & 0,313 & 0,344 & & \\
\hline
\end{tabular}

Fuente: Elaboración propia a partir de datos extraídos del Sistema de Información Geográfica de Parcelas Agrícolas y el Modelo Digital del Terreno de Castilla y León de la Junta de Castilla y León. 


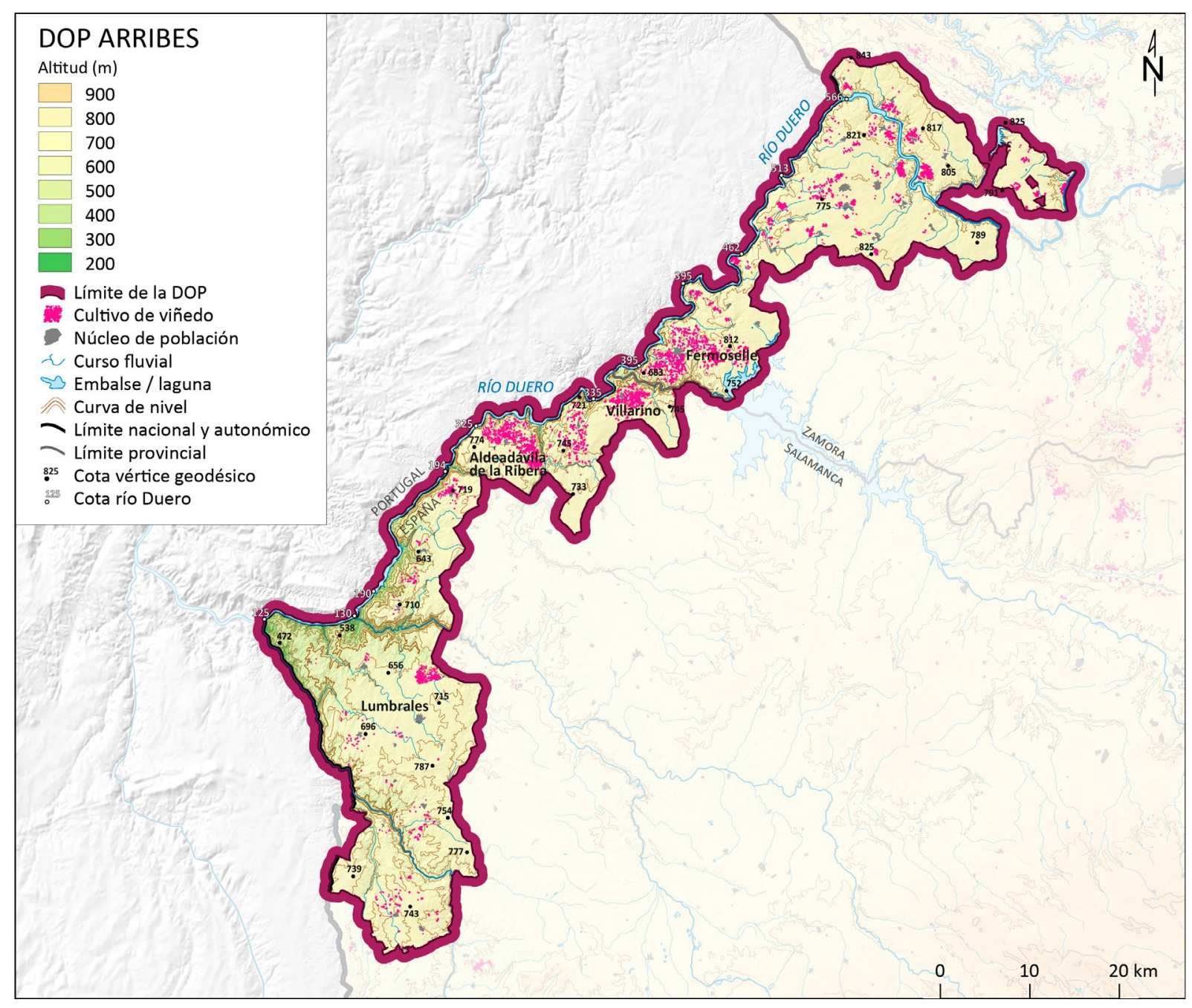

Fuente: Elaboración propia a partir de datos extraídos del SIGPAC y el Modelo Digital del Terreno de Castilla y León de la Junta de Castilla y León.

superficie y modernizando las formas de cultivo, pero son contados. Tan solo una explotación -al margen de una gran finca- sobrepasa las 10 ha, mientras que la mayoría gestiona entre 1 y 5 ha. Fragmentadas, en algunos casos, en decenas de parcelas dispersas por distintos pagos, la explotación del viñedo está, por lo general, en manos de agricultores cuya edad media ronda los 65-70 años, que ya están jubilados, tienen una dedicación parcial o se dedican a otras actividades, pero que, por apego, siguen cultivándolas (Baraja y Herrero, 2018). El mismo perfil se observa en la Sierra de Salamanca, donde un total de 114 viticultores vendimiaron $350.000 \mathrm{~kg}$ de uva en 2017 en las 543 parcelas inscritas en la DOP, lo que representaba una superficie cercana a las 130 ha. En el Bierzo, por último, un total de 2.092 viticultores están vinculados a la DO, trabajando una superficie media de 1,3 ha (Baraja, Herrero, Martínez y Plaza, 2019b).

Como resultado de todo ello, tuvo lugar una fase de depresión profunda derivada de la crisis de los sistemas tradicionales y de la forma de vida de la sociedad que los sustentaba. Por eso, el viñedo, como el resto de cultivos, han retrocedido tanto. Si volvemos al índice 100 para 1985, en 2017 ha caído en el Bierzo a 63,1; a 54,7 en Arribes; a 49,7 en la Sierra de Salamanca; y a 45,5 en Cebreros (Tabla 1). Muchas de las antiguas parcelas de viñedo aparecen hoy abandonadas y una parte de los derechos que generaron en su momento se vendieron a viticultores de 


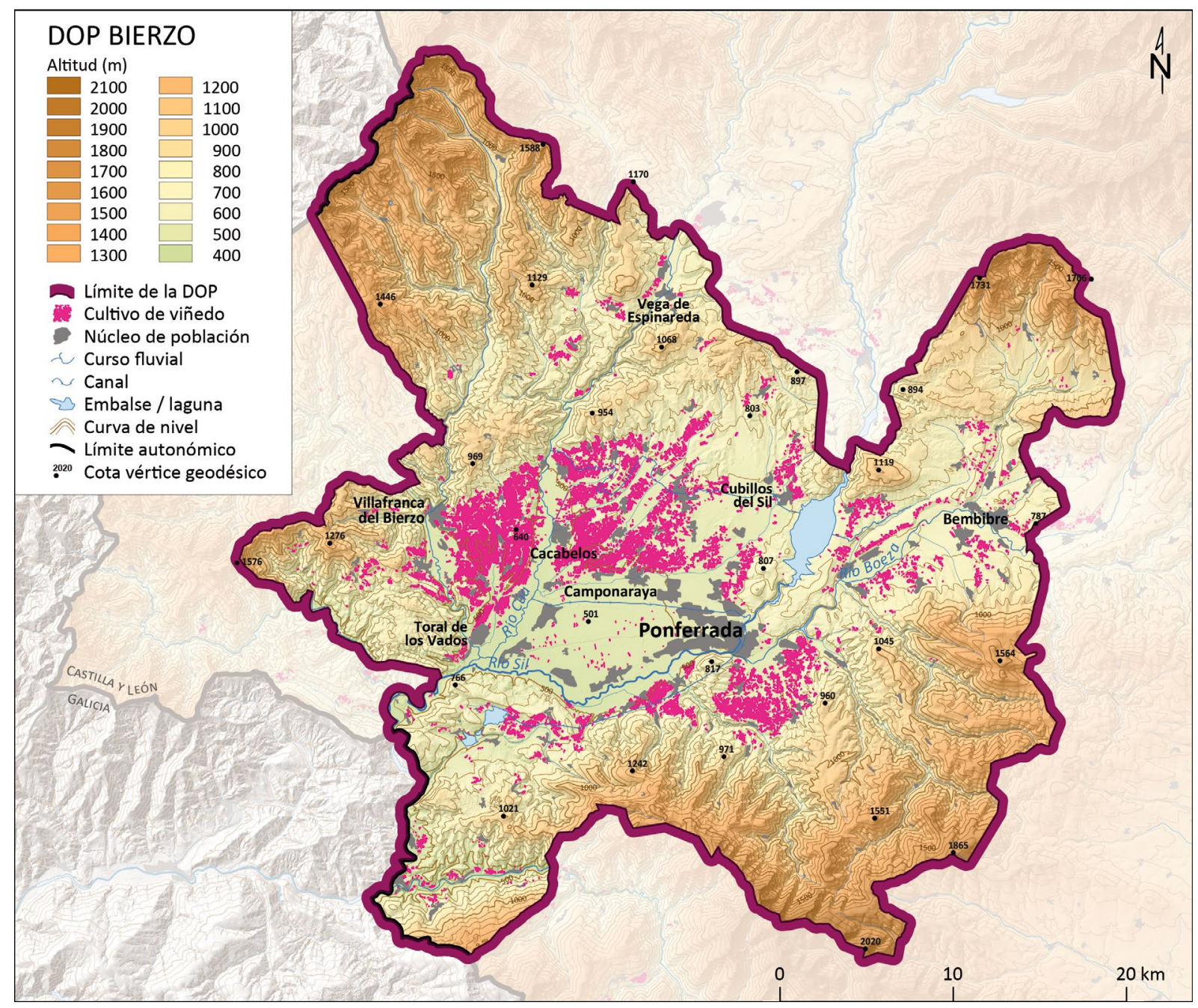

Fuente: Elaboración propia a partir de datos extraídos del SIGPAC y el Modelo Digital del Terreno de Castilla y León de la Junta de Castilla y León.

las comarcas más prósperas apuntadas arriba. Además, los viñedos que perviven se cultivan bajo pautas que tienen no poco de arcaísmo, motivado por la edad media elevada de unos agricultores que, aferrados a prácticas tradicionales, han mantenido el viñedo para el autoconsumo, la venta a comerciales foráneos o la entrega a las escasas cooperativas que aún funcionan.

\section{Resiliencia y adaptación en los espacios vitivinícolas tradicionales: de la fatalidad a la oportunidad}

Paradójicamente, lo que parecía una adversidad insalvable, en las últimas dos décadas se está convir- tiendo en oportunidad, pues "en las áreas económicamente marginales se han favorecido experiencias post-productivas, mientras que la agricultura industrializada es característico de las áreas económicamente favorables" (Binimelis, 2019, p.4). Las preferencias por vinos exclusivos, elaborados en entornos de alta calidad ambiental y cultural, los están sacando de la postración. Son tiempos en los que los valores apuntan a lo singular, al carácter, la integridad, al entorno, al patrimonio... a todo aquello que, en suma, sintetiza el paisaje. Es una tarea que no resulta fácil, como se aprecia en el esfuerzo de los promotores (actores muy singlares) que han buscado el reconocimiento de su calidad: "donde otros vieron viñedos abandonados, vi futuro, trabajo y oportunidades" 


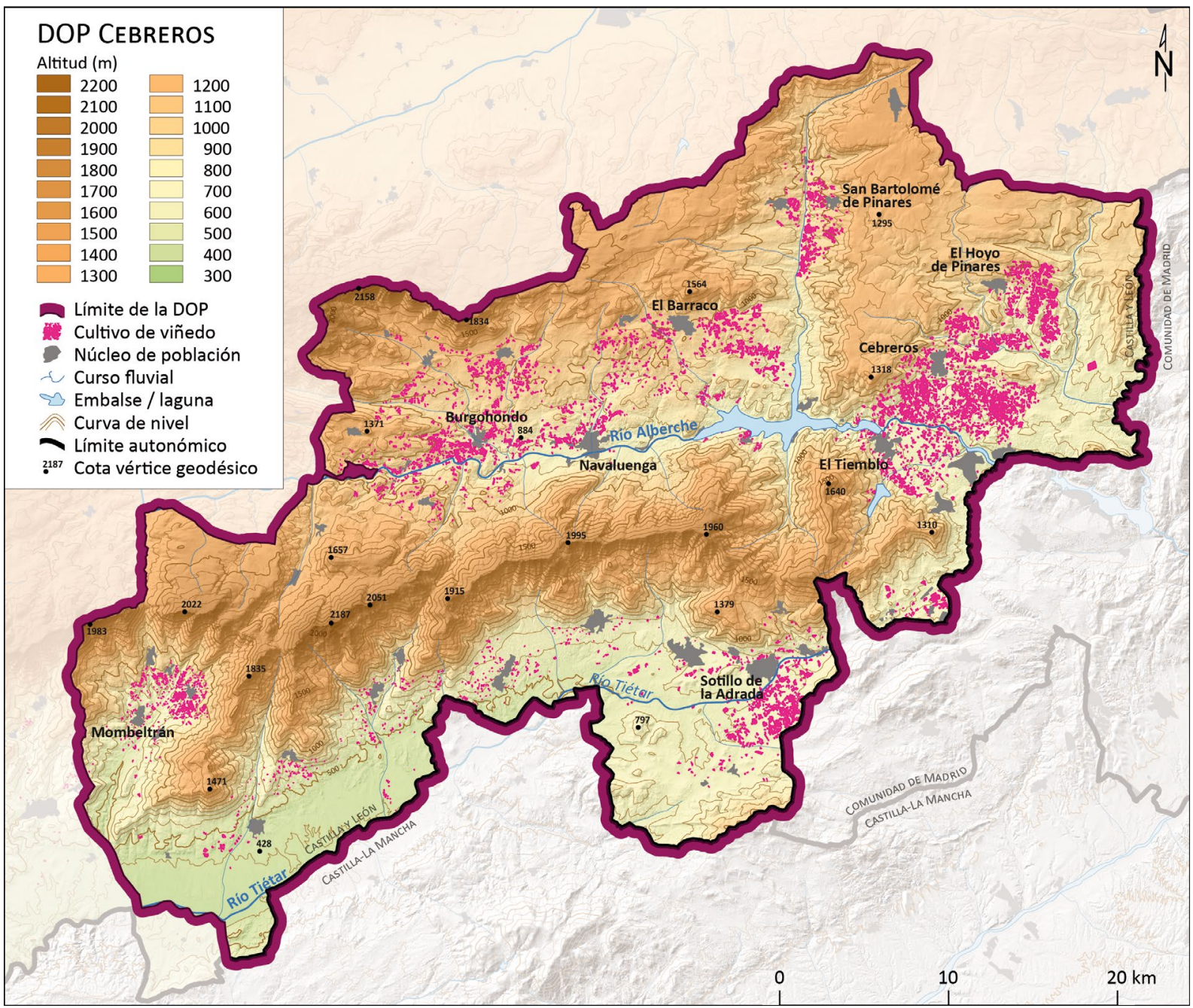

Fuente: Elaboración propia a partir de datos extraídos del SIGPAC y el Modelo Digital del Terreno de Castilla y León de la Junta de Castilla y León.

(señala Rafael Mancebo, presidente de la DOP Cebreros). Casi todos han alcanzado su marchamo DOP en fechas cercanas a nuestros días, aunque habían gozado de ciertas menciones previas: Arribes (DO) en 2007; Sierra de Salamanca (VC) en 2010 y Cebreros (VC) en 2019.

En los documentos técnicos y pliegos de condiciones que aparecen en estos reconocimientos, se destacan rasgos de autenticidad que otras DOP han perdido: (i) las variedades únicas o singulares, alejadas de los estándares que dominan en los espacios más integrados y aclamadas en los foros especializados (Mencía y, más recientemente, Merenzao y Estaladiña en el Bierzo, Juan García en Arribes, Garnacha en
Cebreros y Rufete en la Sierra de Salamanca); (ii) se trata de viñedos antiguos, parcos en producción, pero una de las mejores bazas para elaborar vinos singulares (en Cebreros, el 94\% de las cepas tienen más de 50 años y el $37 \%$ más de 80 ; por el contrario, solo el $1 \%$ tiene una edad inferior a 30 años; en la Sierra de Salamanca, el $80 \%$ del viñedo tiene más de 50 años y el $50 \%$ más de 80 ); (iii) abundan los marcos tradicionales (en Cebreros, el marco $2.5 \times 2.5$ metros, se traduce en una densidad de plantación de 1.600 cepas/ha, y en vaso, para adaptarse mejor a las singulares condiciones edáficas y climáticas).

Por otro lado, se dan otras circunstancias también particulares que conviene considerar. Se constata, en 


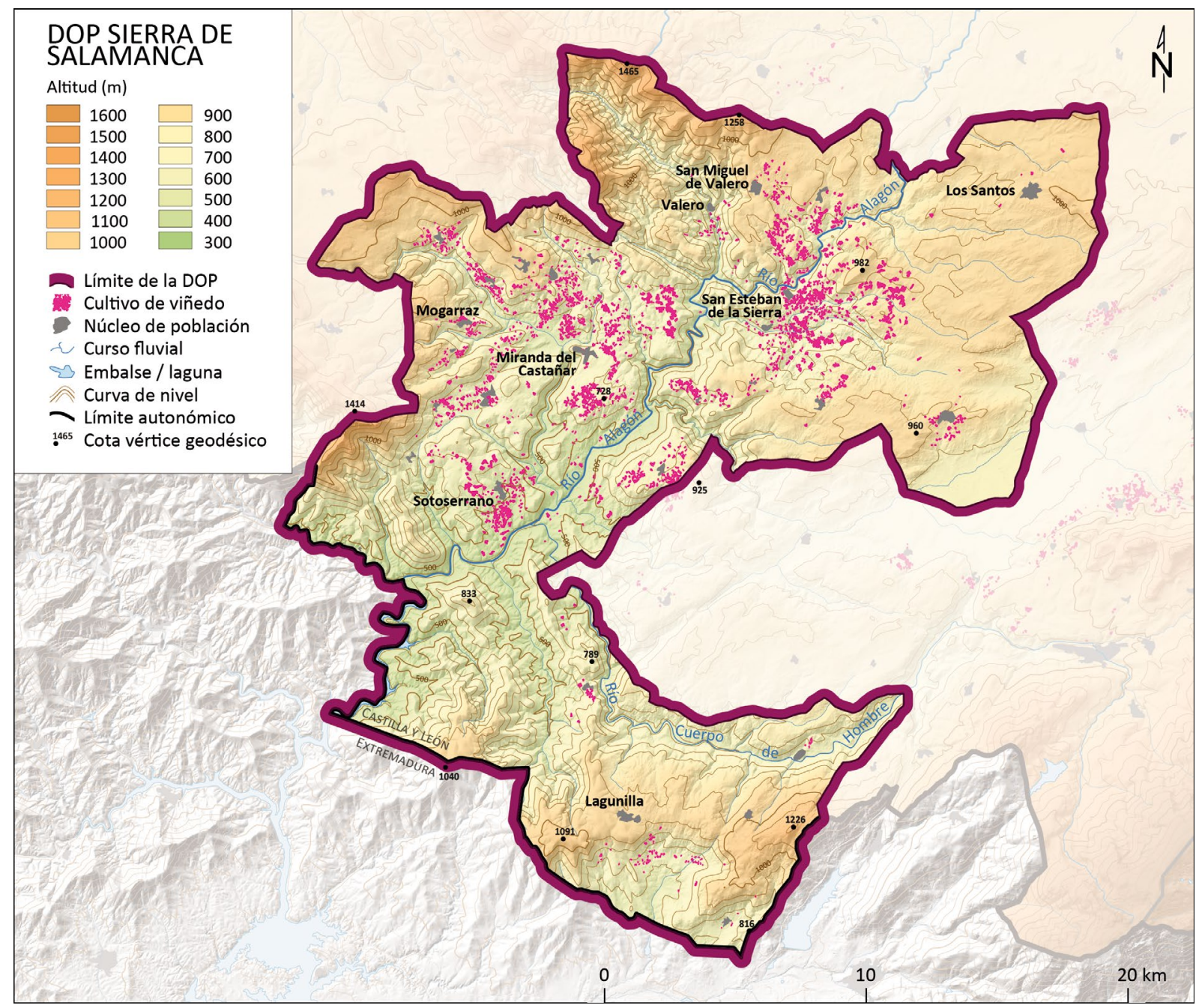

Fuente: Elaboración propia a partir de datos extraídos del SIGPAC y el Modelo Digital del Terreno de Castilla y León de la Junta de Castilla y León.

primer lugar, que el abandono ha sido selectivo, muy intenso en los sectores alejados de los núcleos de población y menos accesibles, y más reducidos en los espacios de menor pendiente y mejor ubicados. En Arribes, por ejemplo, a diferencia de lo que ocurría tradicionalmente, el $75 \%$ de la superficie está ahora en la penillanura, abandonado los bancales que tanta fama dieron a las laderas que miran al Tormes y al Duero en Fermoselle, lo que potencia el contraste con la orilla portuguesa. En segundo lugar, cuando se sigue cultivando, se mantienen prácticas tradicionales, cercanas a los planteamientos ecológicos o de otra concepción agronómica alejada del productivismo (orgánica, biodinámica, etc.). En tercer lugar, también han sido paladines en reivindicar la singularidad dentro de la diversidad. En estos espacios tan variados, cada parcela puede ser diferente en virtud del tipo de suelo, de la orientación o de la altitud.

No es de extrañar que en estos entornos surja una nueva vitivinicultura: la del pago. El ejemplo del Bierzo es elocuente, pues recientemente (agosto de 2019), y tras años de reivindicación, el Ministerio de Agricultura ha aprobado el nuevo pliego de condiciones que, de forma pionera en Castilla y León, introduce una nueva clasificación geográfica de viñedos: vinos de villa (con el $100 \%$ de la uva procedente de parcelas del municipio o pedanía al que se refiera la mención, siempre que el rendimiento sea un $20 \%$ menor al máximo fijado por la D.O.); vinos de paraje 
(100\% de las uvas de un mismo paraje y rendimiento un $25 \%$ inferior al máximo establecido por la DO); vinos de viña clasificada $(100 \%$ de las uvas de una misma parcela o de parcelas colindantes de un mismo paraje, de nombre reconocido en el pliego y que al menos durante 5 años hayan sido tipificados como vinos de paraje y con un rendimiento de la uva un $30 \%$ inferior al máximo fijado por la DO); por último, grandes vinos de viña clasificada (condiciones similares al anterior y tipificados al menos 5 años como vinos de viña clasificada, con un rendimiento de la uva 35\% inferior al máximo fijado por la DO) (Consejo Regulador de la DO Bierzo, 2019) ${ }^{5}$.

Por último, cabe apuntar que estos espacios son representativos de un nuevo tiempo, por el perfil del viticultor, del bodeguero y del enólogo (a veces la misma persona), que va tomando protagonismo y poniendo al día prácticas y discursos. Así, junto a la reconversión de actores tradicionales (bodegas cooperativas que comienzan a abandonar los graneles y embotellan; almacenistas que reducen escala y se especializan), aparece una nueva generación de bodegas y bodegueros con unos rasgos diferentes. Por lo general, tienen raíces en la comarca, pero cada vez son más los que vienen de fuera (en ocasiones de otros países), atraídos por las posibilidades que ofrece un entorno vitivinícola singular. Apuestan por la pequeña escala, tanto por las tiradas cortas como por los viñedos acotados. Parten del reconocimiento de las variedades tradicionales y de los viñedos viejos para elaborar un buen vino, en la seguridad de que tanto importa la bodega como la viña. Apuestan por prácticas agrarias tradicionales, confiando en las que realiza el viticultor local, a quien en muchos casos compran la uva, de quienes aprenden y cuyas enseñanzas asimilan y reelaboran con perfiles modernos para transmitir el carácter singular del entorno. Una parte significativa vincula su negocio vitivinícola con el enoturismo, que se mueve atraído por los valores naturales. Por último, el discurso empleado en la promoción de sus vinos recurre sistemáticamente a destacar los valores naturales y culturales del entorno, que se sintetizan en un paisaje singular (Baraja y Herrero, 2018).

No obstante, para hacer vinos de este perfil, la premisa fundamental es eliminar los obstáculos que condicionan la viabilidad de una viticultura tan singular. Esto implica actuar sobre dos cuestiones básicas: el abandono (provocado por la falta de relevo generacional ante la dureza de trabajar en un terrazgo muy fragmentado) y la pérdida de los elementos que ha- cen de estos entornos espacios de gran valor patrimonial.

\section{El Banco de Tierras del Bierzo: una experiencia contra el abandono del viñedo fácilmente extrapolable a los espacios vitivinícolas de Castilla y León}

En 2017, el informe elaborado por la DOP Sierra de Salamanca (Asociación de Viticultores y Elaboradores de Vino de la Sierra de Salamanca, 2018), destacaba que 114 viticultores recogieron $347.448 \mathrm{~kg}$ de uva en las 516 parcelas amparadas por esta figura de calidad, lo que representaba una superficie cercana a las 105 ha. Sin embargo, la extensión del viñedo supera en la Sierra las 609 ha (utilizando la información obtenida del SIGPAC de 2019), por lo que aproximadamente 500 hectáreas estarían cultivadas por viticultores que no tienen relación con la DOP o, en el peor de los casos, abandonadas. Pero frenar el abandono, involucrar a bodegueros y viticultores en la promoción de los vinos y mantener la función agraria, requiere prácticas imaginativas para una DOP con tan poca superficie, y donde la falta de uva (particularmente de variedades locales y cepas antiguas) puede comprometer las bases sobre las que pretende asentar su futuro. Por esa razón, en ese año se anunciaba desde el Consejo Regulador de la DOP una de ellas: promover un banco de viñedo.

No es un instrumento nuevo. Los bancos de viñedo se inspiran en los bancos de tierras, que en España se fueron desarrollando a partir de las primeras experiencias en Aragón (López, 2017), extendidas posteriormente a Asturias y Galicia, con el fin de favorecer la intermediación entre propietarios y agricultores/ ganaderos para evitar el abandono del campo. En Castilla y León, el Fondo de Tierras Disponibles, previsto en Título $V$ de la Ley Agraria $1 / 2014^{6}$ y configurado como "...un registro administrativo de carácter público [...] que pretende constituirse en un instrumento que facilite la puesta en contacto entre la oferta y la demanda de parcelas agrarias, cultivadas o cultivables, ubicadas en la Comunidad de Castilla y León"7, tiene similar finalidad: luchar contra el envejecimiento y garantizar un relevo generacional, que encuentra serias dificultades por la rigidez del mercado de la tierra, tanto en régimen de arrendamiento como de compra. Llama la atención, sin embargo, el escaso alcance de su función (se han gestionado 3.184 ha en una región con 3,5 millones de ha de tierras de cultivo), pues apenas se ha podido progre- 
sar en la formalización de convenios con administraciones locales para el acceso a las tierras de masas comunes y fincas sobrantes de la concentración parcelaria. La razón es que el proceso de pérdida de población rural y de desagrarización experimentado en Castilla y León, no siempre se ha traducido en abandono. En general, en las comarcas vitivinícolas más dinámicas, lejos de abandonarse y después de un periodo de fuerte reajuste, el interés por disponer de nuevos viñedos ha disparado los precios de la tierra. Entre 2000 y 2017, la hectárea de viñedo de transformación ha pasado de cotizarse, por término medio, de 9.937 a $19.293 € /$ ha. Esta cifra ha ascen- dido en la provincia de Valladolid a casi $30.000 € /$ ha (Ribera del Duero o Rueda) y a $24.910 €$ /ha en Burgos (Ribera del Duero) (Junta de Castilla y León, 2019). Es más, las nuevas plantaciones han tenido que ser temporalmente limitadas por la Consejería de Agricultura, Ganadería y Desarrollo Rural, a instancias de los consejos reguladores (950 ha en la Ribera del Duero en 2019-2022), o bien se han impedido (caso de Rueda) ${ }^{8}$.

Sin embargo, el banco de tierras puede resultar particularmente útil allí donde el abandono es real, o bien donde se busca un nuevo modelo productivo basado en prácticas alternativas que mantengan los valores

FIGURA 7

DISTRIBUCIÓN DE LAS PARCELAS DE VIÑEDO GESTIONADAS POR EL BANCO DE TIERRAS DEL BIERZO EN LA DOP BIERZO

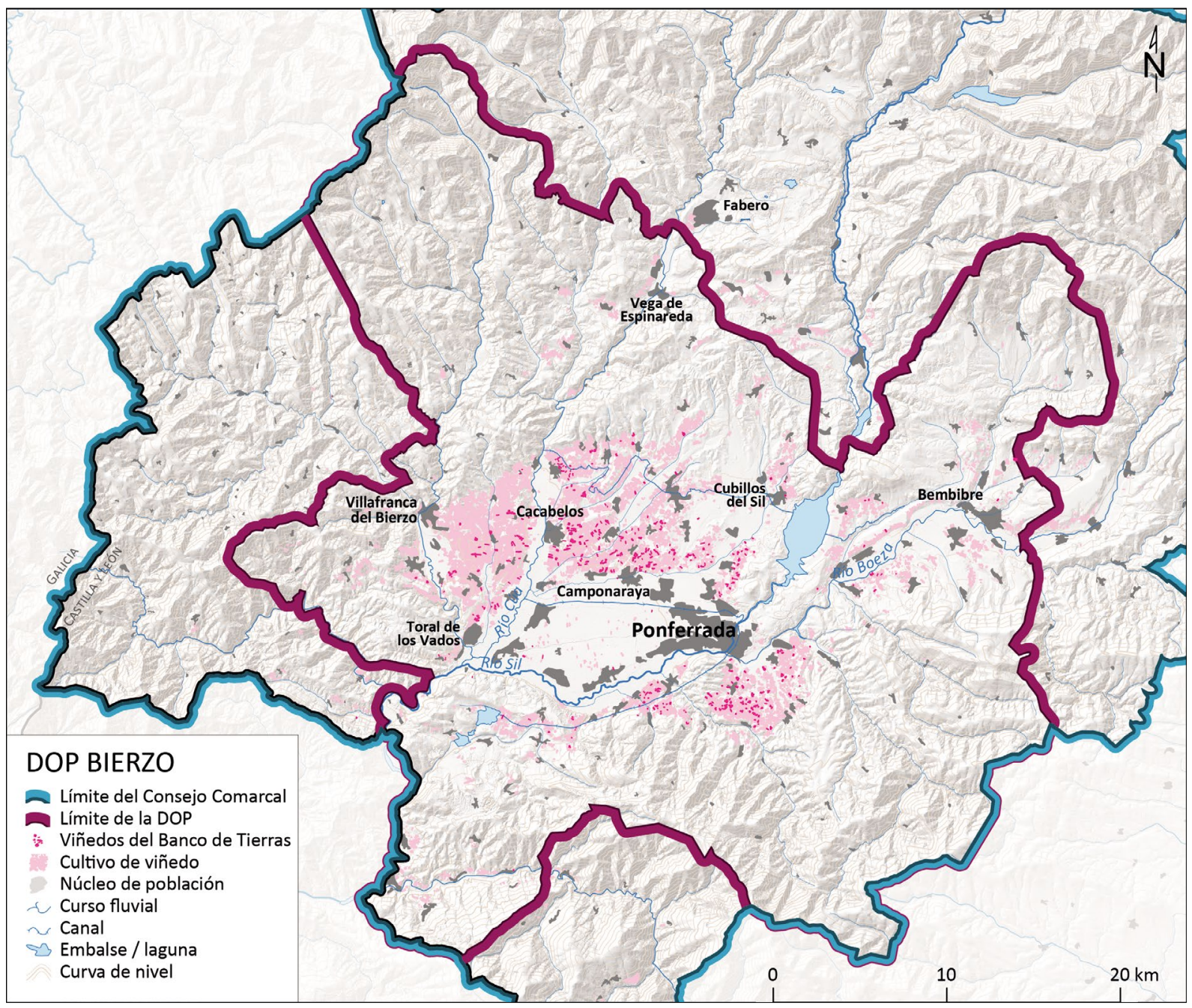

Fuente: Elaboración propia a partir de datos extraídos del SIG del Banco de Tierras del Bierzo, del SIGPAC y del Modelo Digital del Terreno de Castilla y León de la Junta de Castilla y León. 
culturales que dan carácter a los territorios. Es esencialmente lo que ocurre en estos bordes serranos, afectados por el fuerte envejecimiento y la falta de relevo generacional. De esta forma, en 2013, el Consejo Comarcal del Bierzo, animado a impulsar el rejuvenecimiento, la conservación y la actividad agraria en general, puso en marcha un banco de tierras con el fin de movilizar fincas, en una comarca donde "el $70 \%$ de las tierras susceptibles de tener un aprovechamiento agrícola, forestal, ganadero o mixto, están inactivas" (Diario de León, 2012). Hasta la fecha, el Banco de Tierras del Bierzo ha gestionado un total de 2.600 parcelas en la comarca, de las que 1.674 han sido adjudicadas hasta octubre de 2019 (Figura 7).

Asimismo, el Banco ha atendido a 1.520 personas, tanto para facilitar las cesiones y recepciones como para informar, asesorar y hacer cumplir los contratos. Esta gestión clarifica los perfiles y motivaciones de los agentes involucrados: i) el cedente, o cesionario, es una persona mayor (ochenta años de media) que se ve incapaz de mantener en cultivo las parcelas; ii) los herederos que, o bien no viven en la comarca, o bien, por no tener vinculación con el sector, no pueden atender la explotación. En todos los casos, la motivación es clara: no quieren ver abandonados sus campos. En la otra parte, el perfil de quién opta a recibirlas está vinculado a la orientación productiva: si son parcelas hortícolas, el receptor es una persona no profesional y suele haber paridad entre hombres y mujeres. Generalmente, son personas que se encuentran en situación laboral precaria. La crisis de la minería y de las centrales térmicas ha reactivado el interés por la figura del agricultor emprendedor, por lo que entre los demandantes de tierra encontramos a personas que van desde el parado de larga duración hasta el que lo solicita para generar una segunda actividad, pasando por el que quiere la parcela para obtener producto de autoconsumo y vender el excedente.

En el caso del viñedo, la situación es más compleja, como también lo es en el resto de cultivos leñosos, tales como frutales y castaños. Las entrevistas con los responsables de la gerencia del Banco de Tierras del Bierzo clarificaron que predomina el agricultor profesional que está familiarizado con el cultivo; suele contar con una explotación de 3 o 4 ha de media, pretendiendo acceder a otras 2 o 3 ha para ampliar y hacer viable la explotación. Tampoco están ausentes los jóvenes emprendedores que se adentran en el mundo del vino con nuevas ideas.
FIGURA 8

PARCELAS ASIGNADAS DESDE LA CREACIÓN DEL BANCO DE TIERRAS DEL BIERZO POR ORIENTACIÓN PRODUCTIVA (DESDE MARZO DE 2013 HASTA OCTUBRE DE 2019)

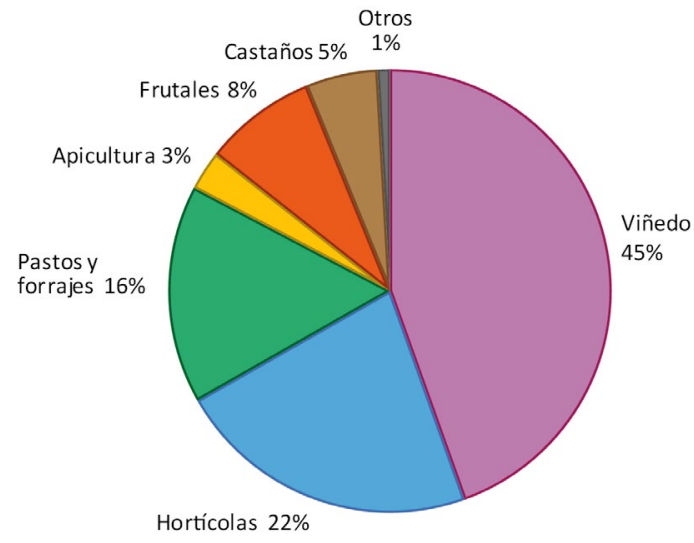

Fuente: Informe de actividad del Banco de Tierras del Bierzo.

Como muestra el gráfico (Figura 8), las principales orientaciones productivas son agrícolas (viñedo, hortícolas, frutales, castaños...) y, muy secundariamente, ganaderas (pastos y forrajes).

Dentro de las primeras, los datos proporcionados por el Consejo Comarcal $^{9}$ apuntan a que, mediante una alianza institucional con la DOP el Bierzo, se han recuperado 120 hectáreas de viñedo entre 2013 y 2018. Distribuidas en 576 parcelas (de un total de 1.397 cedidas o arrendadas), destacan las operaciones en los municipios de Ponferrada, Cacabelos, Arganza, Villafranca, Camponaraya, Carracedelo, Congosto, Borrenes, Priaranza y Toral de los Vados. En 2019 se han incorporado (hasta octubre) otras 40 ha más, distribuidas en 161 fincas con similar ubicación. En total, se han salvado del abandono, o han vuelto a producir, 737 parcelas de viñedo: el $45 \%$ de todas las transacciones realizadas. No es una cantidad desdeñable para una DOP que tiene $2.853,5$ ha inscritas. Son particularmente demandados los viñedos viejos, por lo que desde 2015 se lanzan campañas específicas para la captación de este tipo de parcelas. El procedimiento de cesión ha sido mayoritariamente el "sistema de uso en precario", que garantiza al propietario la recuperación de sus tierras al término del contrato, y se ha dado preferencia a personas vinculadas con el sector. Secundariamente, se han gestionado también arrendamientos y compraventas.

La experiencia del Banco de Tierras del Bierzo, como herramienta de reactivación vitícola, es prome- 
tedora y fácilmente exportable a comarcas como Cebreros, la Sierra de Salamanca o Arribes del Duero. No obstante, no se pueden soslayar las dificultades que en estos espacios conlleva un cultivo trabajoso y no siempre rentable. En este caso, las vías de apoyo abiertas para el mantenimiento del cultivo, tal y como se deduce del análisis de las resoluciones, no están teniendo la eficacia esperada.

\section{El escaso éxito de operaciones orientadas al mantenimiento de los cultivos permanentes en paisajes singulares}

La fragmentación del terrazgo en parcelas abancaladas, las fuertes pendientes o el difícil acceso a las fincas, son circunstancias que, como hemos apuntado, dificultan el manejo moderno y explican el abandono del viñedo, aunque también han hecho posible que se mantengan formas de cultivo tradicionales.

Abundando en esta cuestión, no son pocas las bodegas que reivindican estas prácticas como una particularidad que acrecienta el valor de los vinos, al tiempo que juega un papel clave en el mantenimiento de un rico paisaje cultural. Es este paisaje, junto a los valores naturales intrínsecos a estos bordes montañosos, el que actúa como elemento de atracción de visitantes y, retroalimentando el fenómeno, convierten al turismo en un factor de patrimonialización (Gravari-Barbas, 2014).

Los elementos (materiales e inmateriales) que actúan como vectores patrimoniales son diversos y tienen mucho que ver con la construcción de estos espacios vitivinícolas (Baraja et al., 2017; Baraja et al., 2019c). Bodegas, guardaviñas, caminos, portillos, paredones, bancales, plantaciones, etc., son componentes físicos que focalizan los procesos de patrimonialización. No es de extrañar que, recurrentemente, estos paisajes vitivinícolas aparezcan entre los que optan al reconocimiento por parte de las instituciones. El ejemplo de los Enclaves Territoriales de Interés Cultural (ETIC) de Castilla y León es bien elocuente. A imagen de lo avanzado en el Plan Nacional de Paisaje, en el Libro Blanco de los 111 ETICs de Castilla y León que está elaborando la Consejería de Cultura y Turismo de la Junta de Castilla y León, aparecen diferentes categorías "paisajísticas", entre las que se encuentra la agropecuaria. De los 13 ETIC que la componen, los cuatro vitivinícolas a los que estamos aludiendo, están representados. Estos espacios corresponden a los cultivos tradicionales en las Arribes del
Duero en Fermoselle, en Zamora (donde el viñedo es clave), a los viñedos tradicionales en San Esteban de la Sierra (Sierra de Salamanca), alos viñedos del Bierzo en Corullón y a los cultivos tradicionales en el Paisaje Pintoresco de las Cinco Villas, en Mombeltrán, Ávila (DOP Cebreros).

El valor de los ETIC está, por tanto, reconocido implícita o explícitamente como un paisaje de notable interés cultural. Los beneficios del cultivo en los entornos naturales se hacen patentes en los diferentes documentos de gestión (prevención de incendios, reducción de la erosión, etc.). Desde esta perspectiva, se pone de manifiesto, probablemente más que en ningún otro lugar, las externalidades positivas que los viticultores aportan. Es un rasgo más de las nuevas coordenadas postproductivistas sobre las que estos viñedos cifran su futuro, en un contexto en el que el "mundo rural comienza a ser visto no como una simple superficie de producción sino como un espacio que puede aportar y aporta una serie de valores de sumo interés para una sociedad global cada vez más urbanizada" (Armesto, 2005, p 140).

Si se entienden como un servicio al interés común, parece razonable que estas prácticas sean compensadas. La Ley 45/2007, de 13 de diciembre, para el Desarrollo Sostenible del Medio Rural ${ }^{10}$, ponía el acento en esta cuestión al desarrollar la figura del "contrato territorial", y el RD 1336/2011, de 3 de octubre, por el que se regula, destacaba en su exposición de motivos la necesidad de retribuirlas "como forma de reconocimiento por la sociedad de los servicios y prestaciones de carácter público que generan las explotaciones agrarias, más allá de la retribución derivada de la venta en el mercado de sus productos"11.

Con antecedentes en la legislación francesa y en algunas normativas autonómicas (Rodríguez-Chaves, 2011), los contratos territoriales contemplan la finalidad, entre otras, de “...mantener sistemas agrarios tradicionales de alto valor natural o cultural que en la coyuntura actual tienden al abandono ". A ello se le agrega la mayor sensibilidad a los efectos derivados de la crisis climática, por lo que se apoya la adopción de las acciones que contribuyan positivamente a la conservación del medio ambiente y a mitigar los efectos del cambio climático.

Por esta razón, el Programa de Desarrollo Rural (PDR) 2014-2020 de Castilla y León ${ }^{12}$ financia medidas agroambientales y climáticas, como el apoyo a los agroecosistemas extensivos de secano en humedales de importancia internacional, la apicultura para la 
mejora de la biodiversidad, el aprovechamiento forrajero extensivo mediante pastoreo con ganado ovino o caprino, los cultivos agroindustriales sostenibles, la gestión sostenible de superficies forrajeras pastables y el apoyo a los sistemas tradicionales de pastoreo trashumante, o bien al mantenimiento de razas autóctonas puras en peligro de extinción (Junta de Castilla y León, 2014). Asimismo, el PDR prevé operaciones tendentes al mantenimiento de los cultivos permanentes (olivo, viñedo, almendro, castaño e higuera) en paisajes singulares, justificándolas "por el alto riesgo de abandono de los mismos dada su escasa rentabilidad, así como las dificultades que su mantenimiento conlleva, además de favorecer la existencia de paisajes singulares".

Por primera vez aparece como superficie elegible "una medida de claros efectos paisajísticos" (Junta de Castilla y León, 2014, p. 556). Esta medida, articulada mediante un compromiso o contrato de gestión -asimilable, en términos generales, a los contratos agrarios- está adaptada a espacios como los que estamos describiendo, lo que se hace explícito en las condiciones previstas para acceder a la ayuda: "cultivos permanentes que tengan una densidad de 100 pies por hectárea situadas en terrazas o abancalamientos; existencia de elementos singulares (setos vivos o muros de piedra) en, al menos, cien metros lineales por hectárea; pendiente igual o superior al 10\%; o ubica- ción en los Parques Naturales de Castilla y León", como recoge la Orden AYG/146/2017 (Junta de Castilla y León, 2017) ${ }^{13}$. Pese a que en convocatorias como la de 2017 se estimaba que esta medida podría "afectar a 500 agricultores e implicar a unas 5.000 hectáreas"14, la relación de beneficiarios de estas ayudas en Castilla y León ${ }^{15}$ solo ha ascendido a 37 en 2015, e incluso baja a 28 en la convocatoria 2016, con subvenciones que oscilan entre los 100 y los $1.700 €$, lo que representa un importe total que no llega a los $30.000 €$.

Una parte importante de las solicitudes aprobadas proviene de municipios radicados en las provincias de Salamanca y Zamora, en el entorno de Arribes del Duero, pero sobre todo destacan los situados al sur de Ávila (Arenas de San Pedro y Candeleda), donde abundan los olivares y los frutales. Escasa ha sido la atención al viñedo en esta medida, pues no son muchos los profesionales de la agricultura que quedan en estos entornos. Es, sobre todo, la corta cuantía de la ayuda (100 euros por hectárea) lo que parece justificar el limitado alcance de la operación. En la convocatoria de 2017 se acotó a 30 millones de euros el total presupuestado para el conjunto de medidas agroambientales y clima, de los que solo 100.000 iban destinados a los cultivos permanentes en paisajes singulares. A título comparativo, el programa de cultivos agroindustriales sostenibles estaba dotado con

TABLA 3

RESULTADOS 2019 DE LAS MEDIDAS AGROAMBIENTALES Y CLIMÁTICAS EN EL PDR DE CASTILLA Y LEÓN (2014-2020)

\begin{tabular}{|c|c|c|c|}
\hline & $\begin{array}{l}\text { № contratos actuales } \\
2015-2019\end{array}$ & Unidades & $\begin{array}{l}\text { Importe anual } \\
(€)\end{array}$ \\
\hline Agricultura ecológica (ha) & 275 & 15315 & 2500000 \\
\hline $\begin{array}{l}\text { Agroecosistemas extensivos de secano en humedales de importancia } \\
\text { internacional }\end{array}$ & 276 & 20081 & 1424000 \\
\hline Apicultura para la mejora de la biodiversidad (colmenas) & 398 & 121500 & 1957000 \\
\hline Producción integrada & 40 & 372 & 51520 \\
\hline $\begin{array}{l}\text { Aprovechamiento forrajero extensivo mediante pastoreo con ganado ovino y/o } \\
\text { caprino }\end{array}$ & 1392 & 365500 & 3804500 \\
\hline Cultivos permanentes en paisajes singulares (ha) & 57 & 308 & 26374 \\
\hline Cultivos agroindustriales sostenibles (ha) & 2954 & 20552 & 8506000 \\
\hline $\begin{array}{l}\text { Mantenimiento de razas autóctonas puras en peligro de extinción ( } n \text { o de } \\
\text { animales) }\end{array}$ & 572 & 37458 & 2093000 \\
\hline $\begin{array}{l}\text { Gestión sostenible de superficies forrajeras pastables y apoyo a los sistemas } \\
\text { tradicionales de pastoreo trashumante }\end{array}$ & 4069 & 260300 & 7860000 \\
\hline TOTAL & 10033 & 841386 & 28222394 \\
\hline
\end{tabular}

Fuente: Junta de Castilla y León. Consejería de Agricultura y Ganadería. 
1,5 millones y la remolacha azucarera podía alcanzar una prima de 450 euros/ha.

Todavía, en 2019/20, las disponibilidades presupuestarias referidas al pago de las cinco anualidades de contrato (10 M€), solo alcanzan los 125.000 euros para atender a los paisajes singulares, frente a los 2,5 $\mathrm{M} €$ de los cultivos agroindustriales sostenibles o de la gestión sostenible de superficies forrajeras pastables y el apoyo a los sistemas tradicionales de pastoreo trashumante. La desproporción sigue siendo evidente. En los momentos actuales (Tabla 3), son 57 los contratos en vigor (2015-2019), que agrupan un total de 308 ha.

\section{Gestionar los valores patrimoniales del paisaje vitivinícola: el potencial de las Reservas de la Biosfera}

Conforme a lo previsto en el programa Hombre y Biosfera (MaB) de la UNESCO, las Reservas de la Biosfera (RB) tienen como objetivo último conciliar la conservación del patrimonio natural y cultural con el desarrollo sostenible. Algunas comunidades autónomas, aunque no todas, han apostado por las RB como figuras interesantes para la gestión de sus territorios, integrándolas en las estructuras administrativas regionales. Otras, les han prestado menor atención.

Se ha de considerar que la RB no es una figura de protección de espacios naturales o culturales, sino de investigación, educación, experimentación y difusión de buenas prácticas para la sostenibilidad. En cierta medida, este enfoque nos coloca en el camino que abría la Ley $45 / 2007$, al asumir la idea de la multifuncionalidad del medio rural y de las externalidades positivas de la actividad agraria, y pone en evidencia el alto potencial que tienen herramientas contractuales apenas desarrolladas, como los contratos territoriales de zona rural, previstos en su artículo 16 para "el mantenimiento y la mejora de una actividad agrícola, ganadera y forestal suficiente y que sea compatible con el desarrollo sostenible en el medio rural" (Rodríguez-Chaves, 2011, p.71).

Por otro lado, la idea del paisaje como expresión territorial totalizadora y su alto valor inspirador a la hora de elaborar herramientas y estrategias de gestión, queda plasmada en el Informe de Identificación Paisajística de las Reservas de la Biosfera Españolas, en el Marco del Convenio Europeo del Paisaje, donde se apunta que "si las Reservas de la Biosfera españolas lo aplican como referencia y lo "interiorizan" (...), probablemente se con- vertirían en pioneras a nivel mundial en este sentido" (Sánchez, Sánchez y Martín, 2011, p.9).

Este alineamiento, de objetivos e ideas, entre paisaje y sostenibilidad en las RB es clave para la gestión del territorio en general $y$, particularmente, del paisaje vitivinícola en los entornos frágiles y de alta densidad patrimonial (Baraja, Garcia y Herrero, 2019a), como son los bordes serranos de la cuenca del Duero. Se ha de considerar que una parte de la DO Bierzo está dentro de la Reservas de la Biosfera de Ancares Leoneses, y que la totalidad de la DOP Sierra de Francia y de la DO Arribes quedan bajo la influencia de las Sierras de Béjar y Francia y Meseta Ibérica respectivamente (Figura 9).

Algo similar acontece en el conjunto del país. No faltan experiencias en la gestión del paisaje vitivinícola en particular (Urdaibai, Lanzarote, etc.) y del agrario en general, como los Contracte Agrari de la Reserva de la Biosfera de Menorca (CARB). La experiencia menorquina es aleccionadora a la hora de enfocar la conciliación entre las actividades económicas y la conservación del entorno (Menorca Reserva de Biosfera, 2019). El Catálogo de Experiencias demostrativas en las Reservas de la Biosfera españolas (Organismo Autónomo de Parques Nacionales, 2009) destaca que su objetivo es "compensar a los payeses menorquinos por el hecho de mantener el paisaje de la actividad agroganadera tradicional, una de las señas de identidad y atractivos turísticos que tiene Menorca". Básicamente, la experiencia consiste en "un acuerdo mutuo entre la Administración y la explotación, según el cual la finca se obliga a unos compromisos de prácticas sostenibles. Por su parte, la Administración concede ayudas y compensaciones, así como servicios y formación específica" (Organismo Autónomo de Parques Nacionales, 2009). En la convocatoria de 2018 se planteó como objetivo explícito "reconocer los servicios que los payeses profesionales ofrecen con su trabajo al resto de la sociedad, como la preservación del paisaje", para lo que se concedieron 719.000 euros a un total de 195 beneficiarios (García, 2018). Sobre el potencial de este marco de intervención, tampoco faltan estudios adaptados a espacios de Castilla y León, como los propuestos para la ganadería extensiva en la RB de las Sierras de Béjar y Francia (Vicente, 2013). En suma, las Reservas de la Biosfera pueden asumir el reto de generar un marco de confianza entre productores y bodegueros para facilitar un tipo de prácticas respetuosas con los valores patrimoniales vinculados al paisaje vitivinícola. 


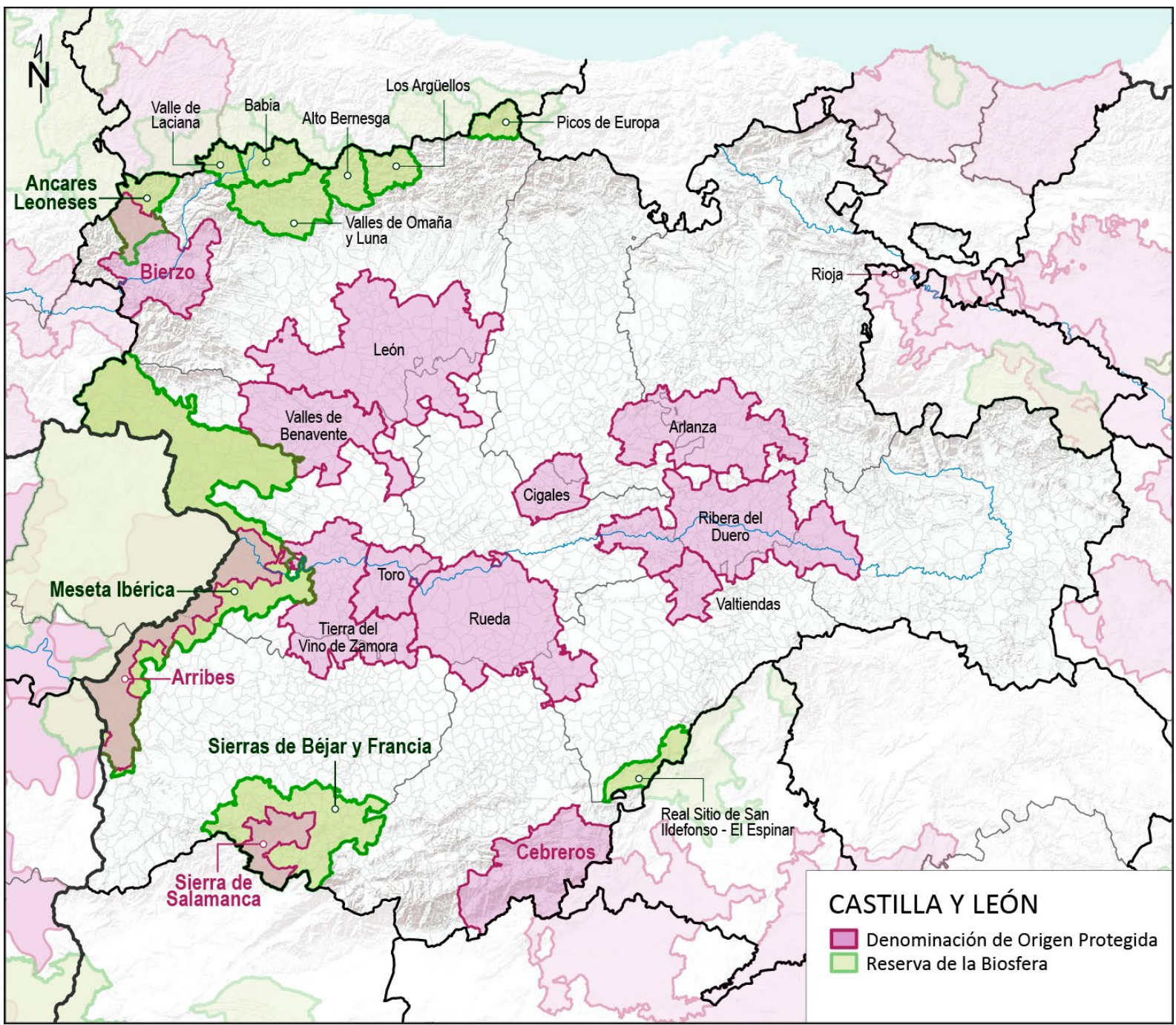

Fuente: Elaboración propia.

\section{CONCLUSIONES}

Al lado de los territorios de la vid y el vino más dinámicos de Castilla y León, asentados en el centro de la cuenca y basados en un modelo abierto a la innovación productiva para ganar en competitividad en los cada vez más exigentes mercados globales, emergen lentamente los territorios que, ubicados en espacios de montaña, serranos o fuertemente abarrancados, apuestan por rescatar los restos más originales que han sobrevivido a la crisis de la agricultura tradicional para, convenientemente reconvertidos, utilizarlos en afianzar un modelo de vitivinicultura basado en la singularidad.
La recomposición de los lazos territoriales de esta agricultura se convierte así en la clave de la diferenciación y en el factor determinante para explicar su reaparición. Por esta razón, las estrategias de supervivencia tienden a poner en valor la calidad ambiental y cultural de los entornos y la integridad de sus contrastados patrones paisajísticos. No obstante, también son espacios que se enfrentan a dificultades específicas. El abandono y la degradación de elementos de alto valor patrimonial es un rasgo particularmente crítico de estos últimos, pues socava su principal fortaleza y acrecienta su mayor debilidad. 
Alguna de las medidas e instrumentos utilizados para combatir estas amenazas están teniendo efectos desiguales. Frente al alto potencial del Banco de Tierras del Viñedo, ensayado con éxito en el Bierzo para luchar contra el abandono del terrazgo, llama la atención el escaso alcance de una medida tan específica como la prevista para favorecer los cultivos permanentes en paisajes singulares del PDR de Castilla y León 2014-2020. Si la escasa dotación no compensa las prácticas que contractualmente deben asumir los beneficiarios, parece razonable buscar patrones de aplicación selectivos que acoten y financien convenientemente a los agricultores comprometidos en entornos precisos. Esto exige un conocimiento profundo del espacio agrario comarcal y una gestión que trascienda la separación convencional entre el patrimonio cultural (en forma de BIC o de Enclaves Territoriales de Interés Cultural) y el natural (en las diferentes tipologías de espacios naturales), lo que sería fácilmente alcanzable mediante la comprensión de los valores del paisaje. En este sentido, una figura promovida por uno de los programas de la UNESCO, la Reserva de la Biosfera, tiene un alto potencial. Este proceso pasa por: i) identificar tales valores, combinando la mirada experta con la opinión de residentes y visitantes, mediante mecanismos de participación convenientemente diseñados; ii) seleccionar los ámbitos paisajísticos (unidades de paisaje) donde estén mejor representados; iii) ponderar las limitaciones y las posibilidades agrarias que ofrecen; iv) implicar a los viticultores; y v) ante unos recursos limitados, concentrar esfuerzos de ordenación y recuperación en los entornos más frágiles y de mayor valor patrimonial.

\section{RECONOCIMIENTOS}

Esta aportación se inscribe en el Proyecto de Investigación I+D CSO2016-79756-P (AEI/FEDER, UE). Ministerio de Economía, Industria y Competitividad, Programa Estatal de Fomento de la Investigación Científica y Técnica de Excelencia, Subprograma Estatal de Generación de Conocimiento, convocatoria 2016.

\section{NOTAS}

1 La Consejería de Agricultura, Ganadería y Desarrollo Rural de la Junta de Castilla y León esgrime recurrentemente este argumento (como también los resultados del informe Nielsen) para demostrar la pujanza del sector vitivinícola. Recuperado de: https://comunicacion.jcyl.es/web/jcyl/Comunicacion/es/Plantilla100Detalle/1281372057130/_/1284777308011/ Comunicacion

2 En Diciembre de 2018, Wine Advocate concedía sus famosos 100 puntos a un vino elaborado en Gredos con la variedad Garnacha. Recuperado de: https://vinos.wine/blog/un-nuevo-vinoespanol-obtiene-los-100-puntos-parker/

3 Así se expresaba, Luis Gutiérrez, catador en España de R. Parker, a propósito de uno de estos vinos, en la DOP Cebreros: "Rumbo al Norte es el más generoso de los vinos de parcela única. Proviene de una parcela de 0.3 hectáreas de vides mixtas de Garnacha y rocas gigantes en suelos arenosos de montaña...". Recuperado de: http://www.ppadvocatewines.com/index.php?id_product $=995 \&$ co ntroller=product\&id_lang $=1$
4 Se entiende por recinto la superficie continua de terreno, dentro de una parcela, con un mismo uso agrícola.

5 Después de un complejo proceso de trabajo iniciado en 2015, el Ministerio de Agricultura Pesca y Alimentación ratificó en 2019 el nuevo pliego de condiciones que recoge esta clasificación de viñedos en unidades geográficas menores. Recuperado de: http://www.crdobierzo.es/es/comunicacion-ficha/noticias/el-ministerio-deagricultura-aprueba-la-nueva-clasificacin-devinedos-de-la-do-bierzo/275/

6 Ley 1/2014 Agraria de Castilla y León. Boletín Oficial del Estado. Recuperado de: https://www.boe. es/buscar/pdf/2014/BOE-A-2014-3562-consolidado.pdf

7 Artículo 79. Creación y características del Fondo de Tierras Disponibles de Castilla y León. Ley 1/2014, de 19 de marzo, Agraria de Castilla y León

8 Boletín Oficial de Castilla y León, no 229, de 27 de noviembre de 2019. 
9 Recuperado de: http://www.bancodetierrasdelbierzo.es/noticias.jsp

10 Ley 45/2007 para el desarrollo sostenible del medio rural. Boletín Oficial del Estado. Recuperado de: https://www.boe.es/buscar/act.php?id=BOEA-2007-21493

11 Real Decreto 1336/2011, de 3 de Octubre, por el que se regula el contrato territorial como instrumento para promover el desarrollo sostenible del medio rural. Boletín Oficial del Estado. Recupera-

\section{REFERENCIAS BIBLIOGRÁFICAS.}

Alario, M., Morales, E. y Molina. I. (2018). Paisajes del vino y desarrollo turístico: la comarca de Rueda. En AEEA (Ed.), XII Congreso Iberoamericano de Estudios Rurales (CIER). Territorios Globales, Ruralidades Diversas. Libro de Actas (pp. 345348). Segovia, España: AEEA.

Alonso, J. L., Aparicio, L. J., y Sánchez, J. L. (2003). Los espacios vitivinícolas en Castilla y León: La evolución hacia un sistema de calidad. Boletín de la Asociación de Geógrafos Españoles, (35), 101122. Recuperado de https://bage.age-geografia. es/ojs/index.php/bage/article/view/445

Armesto, X. (2005). Notas teóricas en torno al concepto de postproductivismo agrario. Investigaciones Geográficas, (36),137-156. Recuperado de http://www.redalyc.org/articulo.oa?id= 17603608

Asociación de Viticultores y Elaboradores de Vino de la Sierra de Salamanca (2018). Dossier Técnico. Recuperado de http://www.dosierradesalamanca.es/wp-content/uploads/2018/04/dossier_ DOP_Sierra-Salamanca.pdf

Baraja, E., Plaza, J.I. y Prada, E. (2017). Atributos y valores patrimoniales de los viñedos tradicionales en las provincias de Zamora y Salamanca: el caso de los Arribes del Duero. En F. Allende, et al. (Ed.), Naturaleza, Territorio y Ciudad en un Mundo Global. Actas del XXV Congreso de la Asociación de Geógrafos Españoles (pp. 1799-1808). Madrid, España: AGE/UAMEdiciones.

Baraja, E. y Herrero, D. (2018). Paisaje y patrimonio vitivinícola en la raya del Duero: nuevos actores y nuevas estrategias productivas en la DO Arribes. En J.A., Rio et al.(Coord.), Libro de Actas XVI Co- do de: https://www.boe.es/buscar/doc.php?id= BOE-A-2011-15567

12 https://agriculturaganaderia.jcyl.es/web/es/desarrollo-rural/programa-desarrollo-rural-castillaleon.html

13 Boletín Oficial de Castilla y León, no 46, de 8 de marzo de 2017

14 Ídem

15 Boletín Oficial de Castilla y León, n201, de 19 de octubre de 2017

loquio Ibérico de Geografía. La Península Ibérica en el Mundo: problemas y desafios para una intervención activa de la Geografía (pp. 14311439). Lisboa, Portugal: Centro de Estudios Geográficos da Universidade de Lisboa.

Baraja, E., García, A. y Herrero, D. (2019a). Gestión del paisaje vitivinícola en las Reservas de la Biosfera españolas. Cuadernos Geográficos, 58(3), 145-168. doi: http://dx.doi.org/10.30827/ cuadgeo.v58i3.8637

Baraja, E., Herrero, D., Martínez, M. y Plaza, J.I. (2019b). Turismo y desarrollo vitivinícola en espacios de montaña con "alta densidad patrimonial". Cuadernos De Turismo, (43), 97-122. doi: https://doi.org/10.6018/turismo.43.04

Baraja, E., Herrero, D., Martínez, M. y Plaza, J.I. (2019c). Atributos patrimoniales y gestión del paisaje vitivinícola en espacios de montaña: la Sierra de Salamanca. Estudios Geográficos, 80(286), 1 - 17. doi: https://doi.org/10.3989/ estgeogr.201921.001

Binimelis, J. (2019). La transición post-productivista del sector vitivinícola de Mallorca (1990-2015). Boletín de la Asociación de Geógrafos Españoles, (80), 1-37. doi: http://dx.doi.org/10.21138/ bage. 2725

Consejo Regulador de la D.O. Bierzo. (2019). El Ministerio de Agricultura aprueba la nueva clasificación de viñedos de la D.O. Bierzo. Recuperado de http:// www.crdobierzo.es/es/comunicacion-ficha/ noticias/el-ministerio-de-agriculturaa prueba-la-nueva-clasificacin-devinedos-de-la-do-bierzo/275/ 
Diario de León (2 de abril de 2018). La campaña de captación de viñedo viejo del Banco de Tierras del Bierzo recupera para la producción 113 parcelas. Diario de León. Recuperado de http://www.diariodeleon.es/noticias/bierzo/campana-captacionvinedo-viejo-banco-tierras-bierzo-recuperaproduccion-113-parcelas_1238774.html

Diario de León (14 de octubre de 2012). El Consejo crea un "banco bueno". Diario de León. Recuperado de https://www.diariodeleon.es/articulo/ bierzo/consejo-crea-Isquo-banco-bueno-rsquo/201210140400001291791.html

Fernández, J. (2018). La diversificación económica en una comarca vitivinícola tradicional: las bases que sustentan el enoturismo en la Denominación de Origen Cigales (Valladolid). Espacio Tiempo y Forma. Serie VI, Geografía, (11), 141-168.doi: https://doi.org/10.5944/etfvi.11.2018.20868

Fernández, J. y Vidal, M.A. (2018). Las rutas del vino como elementos vertebradores del territorio: el ejemplo de Castilla y León. En J.A. Márquez (Ed.) Sistemas productivos con anclaje territorial (pp. 217-227). Huelva, España: UHU.

García, S. (21 de diciembre de 2018). Menorca aprueba ayudas al CARB por 719.000 euros. Menorca. Menorca Local. Recuperado de https://www. menorca.info/menorca/local/2018/12/ 21/645823/menorca-aprueba-ayudas-carb-por719-euros.html

Gravari-Barbas, M. (2014). Winescapes. Tourisme et artialisation, entre lo global et le local. Vinho, Patrimonio, Turismo e Desenvolvimento: Convergencias ao debate e ao desenvolvimiento das regioes vinícolas mundiais. CULTUR, Revista de Cultura e Turismo, 8(3), 238-255. Recuperado de WINESCAPES : TOURISME ET ARTIALISATION, ENTRE LE LOCAL ET LE GLOBAL | CULTUR - Revista de Cultura e Turismo (uesc.br)

Junta de Castilla y León (2014). Orden AYG/1129/2014, de 19 de Diciembre, por la que se regulan las medidas de agroambiente y clima, contenidas en el Programa de Desarrollo Rural de Castilla y León 2014-2020 y cofinanciadas por el Fondo Europeo Agrícola de Desarrollo Rural (FEADER). Boletín Oficial de Castilla y León, 250/2014, de 30 de diciembre de 2014, 87170 a 87209 . Recuperado de http://pac.jcyl.es/web/jcyl/PAC/es/Plantilla 100Detalle/1284385085712/_/1284392998927/ Redaccion
Junta de Castilla y León (2017). Orden AYG/146/2017, de 6 de marzo, por la que se modifica la Orden AYG/1129/2014, de 19 de diciembre, por la que se regulan las medidas de agroambiente y clima, contenidas en el Programa de Desarrollo Rural de Castilla y León 2014-2020 y cofinanciadas por el Fondo Europeo Agrícola de Desarrollo Rural (FEADER). Boletín Oficial de Castilla y León, 46/2007, de 8 de marzo de 2017, 7394 a 7396. Recuperado de https://agriculturaganaderia.jcyl. es/web/jcyl/AgriculturaGanaderia/es/Plantilla 100Detalle/1284567135430/Normativa/ 1284732792103/Redaccion

Junta de Castilla y León (2018). Junta de Castilla y León. Agricultura y Ganadería crea el Salón de Grandes Vinos para impulsar el crecimiento de ventas de las bodegas y dar a conocer la calidad de sus elaboraciones [Comunicado]. Recuperado de https://comunicacion.jcyl.es/web/jcyl/ Comunicacion/es/Plantilla100Detalle/ $1281372057130 /$ / $1284777308011 /$ Comunicacion

Junta de Castilla y León. (2019). Anuario de estadística agraria de Castilla y León 2017. Recuperado de https://agriculturaganaderia.jcyl.es/web/es/ estadistica-informacion-agraria/anuarioestadisticas-2017.html

López, F. (2017). El efímero banco de tierras de Aragón. Revista Jurídica de Asturias, (40), 21-28. Recuperado de http://reunido.uniovi.es/index.php/ RJA/article/view/11931/11009

Martínez, M., Baraja, E. y Molinero, F. (2019). Criterios de la UNESCO para la declaración de regiones vitícolas como paisaje cultural: su aplicación al caso español. Boletín de la Asociación de Geógrafos Españoles (80), 1 - 33. doi: http://dx.doi. org/10.21138/bage.2614

Menorca Reserva de Biosfera. (2019). Menorca Reserva de Biosfera. Recuperado de http://www. biosferamenorca.org

Organismo Autónomo de Parques Nacionales (2009). Catálogo de experiencias demostrativas en las Reservas de la Biosfera Españolas. Recuperado de: http://rerb.oapn.es/images/PDF_publicaciones/ Catalogo_experiencias_demostrativas_Reservas_ Biosfera_espanolas.pdf

Plaza, J.I. y Fernández, R. (2018). Promoción y difusión de los valores asociados al paisaje patrimonial del viñedo a través de iniciativas turísticas: el 
ejemplo de las denominaciones de origen Toro y Tierra del Vino. En Asociación Española de Economía Agraria (Ed.), XII Congreso Iberoamericano de Estudios Rurales (CIER). Territorios Globales, Ruralidades Diversas. Libro de Actas (pp. 398401). Segovia, España: Asociación Española de Economía Agraria.

Plaza, J.I., Fernández, R. y Herrero, D. (2019). Las bodegas tradicionales y otros bienes patrimoniales en el paisaje vitivinícola de los «Valles de Benavente» (Zamora). Recursos territoriales para el turismo. En Asociación Española de Geografía (Ed.), Crisis y espacios de oportunidad. Retos para la Geografía. XXVI Congreso de la Asociación Española de Geografía. Libro de Actas (pp. 12611275). Valencia, España: Asociación Española de Geografía y Universitat de València.

Rodríguez-Chaves, B. (2011). El contrato territorial y el contrato territorial de zona rural: dos instrumentos para promover una gestión sostenible del medio rural. Ambienta: La revista del Ministerio de Medio Ambiente, (97), 66-82. Recuperado de https://sites.google.com/gl.miteco.gob.es/ revistaambienta/hist\%C3\%B3rico-revistas/97? authuser $=0$

Ruiz, A. R. (2013). Producción agroalimentaria de calidad y postproductivismo agrario: El caso de los vinos de pago en Castilla-La Mancha. Anales de
Geografía de la Universidad Complutense, 33(2), 137-154. doi: https://doi.org/10.5209/rev_ AGUC.2013.v33.n2.43007

Sánchez, L., Sánchez, L. y Martín, A. (2011). Identificación paisajística de las reservas de la biosfera españolas en el marco del Convenio Europeo del Paisaje. Recuperado de http://terrasdomino.deputacionlugo.org/docs/conoce/fichas/espana/ Informe\%20identificacion\%20paisajistica.pdf

Serrano, I. (30 de noviembre de 2017). Sierra de Salamanca marca otro récord en cantidad de uva y calidad del vino. El Norte de Castilla. Recuperado de https://www.elnortedecastilla.es/salamanca/ sierra-salamanca-marca-20171130010445-nt. html

Vicente, F.M. (2013). Contratos ambientales y ganadería extensiva. Estudio aplicado a la Reserva de la Biosfera de las Sierras de Béjar y Francia (Tesis doctoral). Recuperado de https://ebuah.uah.es/ dspace/bitstream/handle/10017/20336/ Tesis\%20F.\%20Vicente\%20Amores.pdf;jsessionid =F3A7E20E1FAC5E29A858F4322E74C000?seque nce $=1$

Vinos.Wine. (2018). Un nuevo vino español entra en la lista de los 100 puntos Parker [Entrada en un blog]. Recuperado de https://vinos.wine/blog/ un-nuevo-vino-espanol-obtiene-los-100-puntosparker/ 
